\title{
Decorating soft electrified interfaces: from molecular assemblies to nano-objects
}

\author{
Lukasz Poltorak, ${ }^{1}$ Alonso Gamero-Quijano, ${ }^{2}$ Grégoire Herzog, ${ }^{2 *}$ Alain Walcarius ${ }^{2 *}$ \\ ${ }^{1}$ Delft University of Technology, Department of Chemical Engineering, Van der Maasweg 9, \\ 2629 HZ Delft, The Netherlands \\ ${ }^{2}$ Laboratoire de Chimie Physique et Microbiologie pour l'Environnement (LCPME), UMR \\ 7564, CNRS-Université de Lorraine, 405 Rue de Vandoeuvre, 54600 Villers-lès-Nancy, France \\ *Corresponding authors: gregoire.herzog@univ-lorraine.fr; alain.walcarius@univ-lorraine.fr
}

This document is a postprint. Final version has been published in Applied Materials Today 2017, 9, 533-550 (http://dx.doi.org/10.1016/j.apmt.2017.10.001).

\begin{abstract}
The interface formed between two immiscible electrolyte solutions (ITIES) constitutes a fantastic playground for the investigation of charge (under the form of either ion or electron) transfer processes. We have reviewed here the routes for the modification of such soft interfaces by an accurate electrochemical control. The three main strategies developed in the past four decades include (i) the electrochemically controlled assembly of molecules and nano-objects; (ii) the in-situ electrogeneration of nanomaterials and (iii) the use of ex-situ synthesised membranes. Applications of functionalized ITIES in the fields of redox catalysis and electroanalysis of modified soft interfaces are also discussed.
\end{abstract}

\section{Keywords}

Functionalized ITIES; liquid-liquid interface; nanomaterials; membranes; electrochemistry. 


\section{Introduction}

The interface formed between two immiscible liquid phases, or soft interface, holds a number of qualities over solid - liquid interfaces [1]. First of all, soft interfaces can be considered free from defects down to the molecular level which leaves out the preferential nucleation sites. They can also be considered as self-healing and renewable as shaking or stirring will ultimately lead to their re-formation. Their amphiphilic character favours the self-assembly of surface active species and nanoscale objects [2] and reactants can be separated between the two immiscible phases [3]. The discontinuous properties of interfacial region can be harnessed to design and deposit materials with Janus properties [4]. The utility of the soft junctions can be further increased when each phase contains mutually insoluble salts, allowing the polarisation of these soft interfaces. Charge transfer reactions can thus be controlled by the application of a potential difference across the interface for either the formation and/or the characterisation of nanomaterials opening new avenues to study the interface [2].

Since the pioneering work of the groups in Montpellier (France) [5-7] and in Prague (then Czechoslovakia) [8] during the sixties and the seventies, the polarizable liquid - liquid interface is known as the interface between two immiscible electrolyte solutions (ITIES) in the electrochemical community [9]. The interfacial polarization is purely an ionic process whereas interfacial charge transfer reactions can be the result of electron or ion transferring across the interface. The description of these mechanisms related to charge transfer reactions are well documented in the literature and are reminded in the supporting information (Figure SI1 and text associated). In the past two decades, functionalization and modification strategies have been developed in order to extend the range of properties of such soft interfaces, and thus their electrochemical features, or to characterize the modified layers by electrochemistry at the ITIES. The modification routes can be divided into three main categories as depicted in Figure 1. The first one is based on (self-) assembly of nanoparticles or amphiphilic molecules at the liquid - liquid interface as well as preformed modifiers that reside at the interface as a consequence of external polarization. The second approach lays in electrochemically triggered interfacial depositions. These can result in (i) interfacial precipitation proceeded by ion transfer reaction or in (ii) reduction of deposit precursor driven by heterogeneous or homogeneous electron transfer reaction. The third approach utilizes ex situ preformed support, usually being a membrane with each side wettable by contacting phase. 


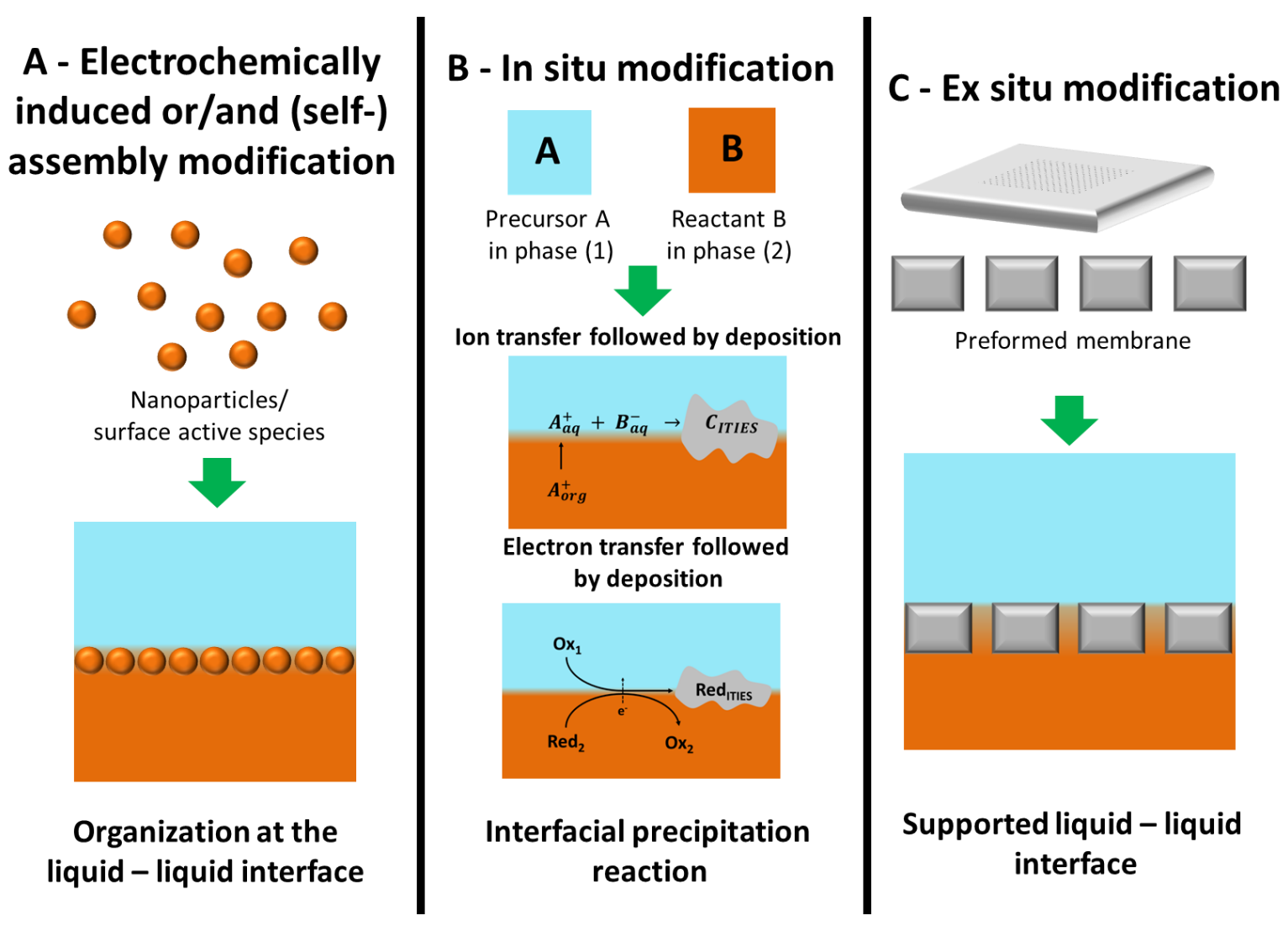

Figure 1. Three main routes used for electrified liquid - liquid interface decoration: (A) selfor electrochemically driven assembly approach, (B) in situ modification and (C) ex situ modification.

The review article is articulated around these three interface modification strategies. Finally, we will give an overview of some applications and indicate challenges in the field of soft interface modification.

\section{Electrochemically induced modification and assembly}

The ITIES modification with nanoparticles (NP), nanotubes (NT), nanosheets (NS) or amphiphilic molecules, which are likely to undergo spontaneous interfacial organization, will be referred to as the assembly induced modification. In all cases considered in this section, the modification was completed after the addition of an available modifier (NP, NT, NS, or molecular species) to one of the immiscible phases. 


\subsection{Molecular assemblies}

Discontinuous properties of the liquid - liquid interface create ideal conditions for amphiphilic molecular assemblies. An intuitive example is the adsorption of phospholipids at the liquid liquid interface forming a monolayer (see Figure 2A), which can be considered as half of a biological membrane [10]. Without any doubt, lipid monolayers at soft liquid junctions provide an interesting alternative to solid - liquid bio-interfaces. In that regard, the highest advantage arise from the combination between the ionic currents that can be measured with the help of the electrified liquid - liquid interface and straightforward - self-assembly driven - interfacial modification method. In a set of successive works, Jänchenova et al. [11-13] have shown that electrochemistry at the ITIES modified with lecithin can deliver information concerning (i) phospholipids adsorption, (ii) monolayer stability, (iii) ion pairing, (iv) acid-base equilibria, (v) association/dissociation between ion and the lipid polar head group and (vi) transmembrane ion transfer reactions. It was found for instance that the electrochemically driven transfer of small ions is undisturbed in the presence of spontaneously assembled lipid monolayer. The temperature, length of saturated alkyl chains of the phosphatidylcholines [14], presence of the divalent cations like $\mathrm{Ca}^{2+} / \mathrm{Mg}^{2+}$ [15] or the packing density of the dilauroylphosphatidylethanolamine [16] were optimised to control the phase transition of lipid monolayer adsorbed. In general, only the compact monolayers, in a liquid condensed phase, were able to affect the rate of ion transfer for ions like $\mathrm{ClO}_{4}^{-}, \mathrm{TMA}^{+}$or $\mathrm{TEA}^{+}[14,15]$. It was also found that external polarisation can disrupt the monolayer and affecting its permeability as deduced from electrocapillary measurements [17-19]. Similar findings [20] showed that phospholipids form 'island-like clusters', which partially cover the interface and ion transfer occurs through cluster-free domains. In order to control a compactness of the adsorbed monolayer, the surface pressure control - with the Langmuir trough technique - was introduced $[21,22]$. Even though the monolayer quality could be controlled by lateral compression, the large planar area gave rise to a significant potential distribution. Moreover, for higher surface pressure the phospholipids tend to desorb from monolayer and dissolve in the organic phase. To overcome such difficulties the organic phase (o-nitrophenyloctylether) was gelled with poly(vinyl chloride) and immersed onto the compact phospholipid monolayer preformed at the aqueous phase surface[23,24]. Various electrochemical techniques (e.g. cyclic and differential pulse voltammetries, and AC voltammetry) were used to study the interaction between drug molecules (propranolol[23], metoprolol [23], tracine [23,25], aminacrine [25], velnacrine [25] and proflavine [25]) and phospholipid monolayers having a different composition. The 
relevance of this studies primarily plays a role in pharmacokinetics and drugs screening as the electrochemical information can be directly translated into partitioning of a drug molecule between the aqueous and lipid phases [10]. Broader image of the ITIES modified with the phospholipid monolayers is available in the set of very well written review papers devoted to this topic [10,26,27].
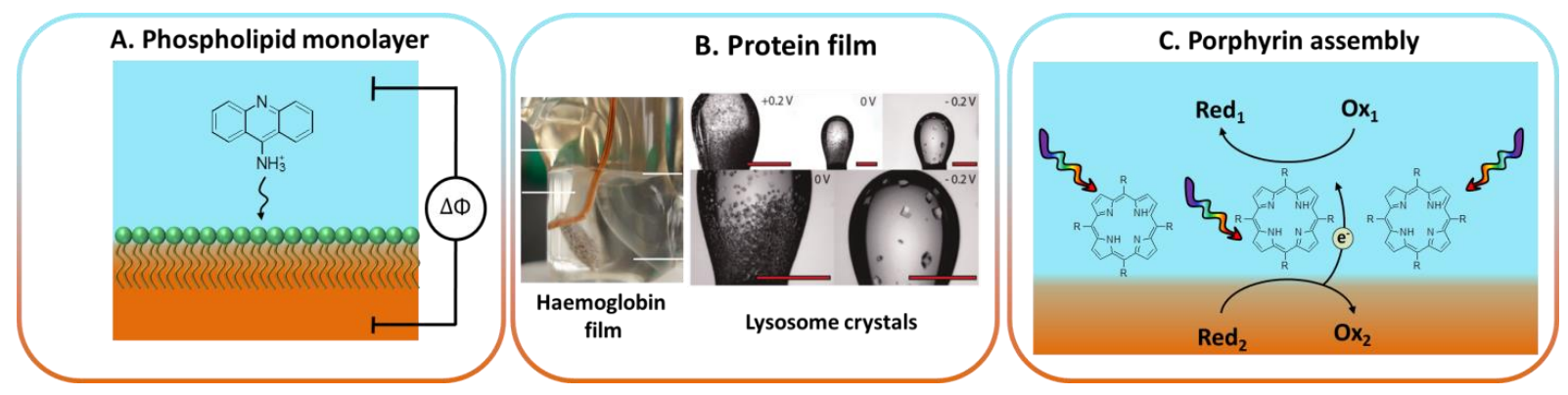

Figure 2. Different approaches related to a liquid - liquid interface decorated with molecular species. A - gives the interface modified with a lipid monolayer with corresponding aminacrine transfer; B images showing two examples of electrochemically deposited proteins at the ITIES (photo of a Haemoglobin film from ref. [28] and pictures of Lysosome crystals adapted from ref. [29]; C-schematic representation of the photoinduced electron transfer reaction mediated by interfacially assembled porphyrins.

Liquid - liquid interface can be also decorated via voltage induced adsorption of biological and synthetic macromolecules [28,30-53]. Interfacial behaviour of these species gives very characteristic voltammetric fingerprints: (i) peak to peak separation deviates from 59/z mV; (ii) reverse peaks are terminated by the abrupt drop in current; (iii) charge transfer peak current at macroscopic liquid - liquid interface do not follow $i \propto \sqrt{v}$ ( $v$ being scan rate) dependency and (iv) shift of the peak position towards higher $\Delta_{\text {org }}^{a q} \Phi$ for increasing concentration of interfacially active species - indicating higher resistance to the charge transfer reaction. These indications were observed for electrochemically driven interfacial adsorption of few class of macromolecular species including polyelectrolytes [30-39], polyamidoamide [40-43], polypropylenimine [44] and poly-L-lysine [45] dendrimers among others [46,47] peptides $[48,49]$ and proteins [28,50-53]. The interfacial adsorption of biological macromolecules brings exciting applications towards the field which are still not sufficiently studied. For instance, the accommodation of the transmembrane proton pump - bacteriorhodopsin - within the lipid monolayer deposited at the liquid - liquid interface allowed photoinduced proton 
transfer to the organic phase [54]. In addition to practical limitation related to protein denaturation [55,56], set of works published more than 20 years ago left out unfinished debate concerning the mechanism of the bacteriorhodopsin assisted proton transfer across liquid liquid interface [55]. Another protein, lysosome, can be crystallized at the water - 1,2dichloroethane (DCE) interface via external polarisation [29]. As shown in Figure 2B positively charged protein adsorption at the positive potential values gave large amount of small crystal whereas negative polarisation resulted in a formation of well separated and large crystals. Electrochemically driven protein film deposition at the water- DCE was also reported for haemoglobin [28] - see Figure 2B - and cytochrome $c$ [57].

Amphiphilic molecules can self-assemble at the liquid - liquid interface, which results in a drop in interfacial tension. This is desirable in detergency, emulsion stabilization, oil recovery, foams etc. Ionic surface active species are responsible for destabilising the interface upon the application of a potential. This was described as electrochemical instability by Kakiuchi $[58,59]$. The potential induced interfacial adsorption of ionic species $\left(\Delta_{\text {org }}^{a q} \Phi^{a d s}\right)$ reaches its maximum value around the standard ion transfer potential of surface active ion $\Delta_{\text {org }}^{a q} \Phi_{i}^{0}$. The resulting drop in interfacial tension leads to thermodynamic instability that is compensated by local emulsification or lateral Marangoni type of movements induced by surface tension gradients [60]. Voltammetric characteristics of electrochemical instability are dependent from experimental time scale and manifest themselves as the irregular current spikes in the vicinity of the $\Delta_{o r g}^{a q} \Phi_{i}^{0}$. Such a behaviour was confirmed for anionic [61-64], cationic [61,65] surfactants and Triton X-405 used as the complexation agent for facilitated transfer of alkalineearth metals [66].

Over the last 30 years, some attention was devoted to interfacial behaviour of molecular chromophores that upon irradiation can induce heterogenous electron transfer reaction across the soft junction. In this regard, the physicochemical properties of the liquid - liquid interface allows (i) the separation of photolysis products based on their lipophilicity and as a consequence partially restricts the back electron transfer (recombination) reactions; (ii) accommodation of amphiphilic chromophores near or at the liquid - liquid interface; and (iii) transforming absorbed photon into useful photocurrent. One of the first examples of the photo-induced electron transfer across the electrified liquid - liquid interface was recorded between the $\left[R u(b p y)_{3}\right]^{2+}$ complex dissolved in the aqueous phase and the electron acceptor $-7,7,8,8$ tetracyanoquinodimethane (TCNQ) present in DCE [67]. Following reports are almost 
exclusively focused on photoinduced electron transfer mechanism between water soluble, interfacially adsorbed porphyrins and quenchers dissolved in the organic phase (see Figure 2C). It was found for instance that zinc tetrakis(carboxyphenyl)porphyrin (ZnTPPC) [68-70], zinc meso-tetra-N-methyl-4-pyridium (ZnTMPyP) [71,72] or zinc meso-tetra-sulphonatophenyl (ZnTPPS) [71,72] can all undergo Galvani potential dependant interfacial adsorption as deduced from voltammetric and electrocapillary curves characteristic or molecular insight from the interface given by potential modulated fluorescence spectroscopy [73], second harmonic surface generation spectroscopy [74] or quasi elastic laser scattering [74,75]. Fermin et al. investigated photo responses of the porphyrin dimers formed between $\mathrm{ZnTMPyP}^{4+}$ and $\mathrm{ZnTPPC}^{4+}$ or $\mathrm{ZnTPPS}^{4+}$ and the quencher dissolved in the organic phase [72]. Although formation and the interfacial adsorption of net neutral dimers was found for both cases only the interfacial orientation of $\mathrm{ZnTMPyP}^{4+}-\mathrm{ZnTPPS}^{4+}$ allowed substantially higher photoresponse recordings as compared to monomeric $\mathrm{ZnTPPC}^{4+}$. Photoinduced electron transfer reaction was also observed for similar porphyrin dimer and hexanethiolate monolayer protected gold nanoclusters dissolved in the DCE phase [76]. ZnTPPS ${ }^{4+}$ association with positively charged polyallylamine polyelectrolyte and polyamidoamine dendrimers can also contribute to photocurrent amplification [77]. The best performance found for dendrimer-porphyrin conjugate was attributed to electrochemically driven interfacial deposit formation with high porphyrin loading and stable associate formation [41]. Considerable attention was also devoted to electrocatalytic properties of Co porphyrins self-assembled at the liquid - liquid interface for oxygen reduction reaction [78-83].

\subsection{Metal nanoparticles}

Optical, magnetic and electronic properties of NPs can be tuned by controlling their shape and dimension. In order to exploit these properties, they can be self-assembled at the interface between two immiscible phases [2,84-88]. Once the NPs are located at the liquid/liquid interface, the total energy change, $\Delta E$, of the biphasic system before and after NP adsorption can be expressed by the following expression [86]:

$$
\Delta E=-\frac{\pi r^{2}}{\gamma_{O A}}\left[\gamma_{O A}-\left(\gamma_{P A}-\gamma_{P O}\right)\right]^{2}
$$

In this equation, $r$ is the NP radius, $\gamma_{O A}, \gamma_{P A}, \gamma_{P O}$ are the organic-aqueous, particle-aqueous and particle-organic interfacial tensions. The expected diminution of energy is due to the 
reduction of the surface area of contact between the organic and the aqueous phases, which is replaced by an area of contact between the NPs and the two phases. Young's equation describes the relationship between the different interfacial tensions [86].

$$
\cos \theta=\frac{\gamma_{P O}-\gamma_{P A}}{\gamma_{O A}}
$$

where $\theta$ is the contact angle formed by the particle at the organic-aqueous interface. A hydrophilic NP will sit on the aqueous side of the interface and $\theta<90^{\circ}$. Inversely, a lipophilic NP will sit on the organic side of the interface and $\theta>90^{\circ}$. Combining equations (1) and (2), the reduction of the surface energy can be expressed as follows [86]:

$$
E=\pi r^{2} \gamma_{O A}(1+\cos \theta)^{2}
$$

The NP assembly at the liquid-liquid interface is then governed by three main factors: (i) the NP dimension, (ii) the organic-aqueous interfacial tension and (iii) the wettability of the NP expressed by the contact angle. The surface energy is proportional to the square of the NP radius with the consequence that microparticles assemble irreversibly at the organic-aqueous interface, whereas surface energy for NPs is much smaller and allows dynamic adsorption/desorption processes. The NP wettability can be addressed by changing the nature and the charge of the NP coating.

The assembly of NPs at the organic-aqueous interface is triggered by an external parameter. It can be the addition of ethanol to the aqueous phase, salts or by covalent cross-linking to modify the contact angle and the interfacial tension. NP assemblies can also be stabilised by bringing energy to the biphasic system via the application of a potential difference across the organicaqueous interface [89]. Cyclic voltammetry studies in the presence of colloidal gold (NP diameter $=1.5 \mathrm{~nm}$ ) in the aqueous phase showed a broad peak at negative potentials. The linear dependency of the peak current with scan rate suggested adsorption / desorption process controlled by the potential (Figure 3A). This was further evidenced by AC voltammetry as the excess charge was observed at negative potential difference (i.e. when anions were accumulated on the aqueous side of the interface). The excess charge increased with the concentration of citrate-stabilised $\mathrm{Au}$ NPs in the aqueous phase. This potential-dependent adsorption / desorption phenomenon was later confirmed by calculations of the nanoparticle energy profile at the ITIES demonstrating that the potential for the control of the adsorption and desorption of $2 \mathrm{~nm}$ NPs was within the range of the ITIES polarization window [90]. Au NPs self-assembly can also be stabilised by the presence of tetrathiafulvalene (TTF) in the organic phase [91]. This 
small redox electron donor displaced citrate ligands surrounding the Au NPs by a charge transfer reaction, which resulted in the oxidation of the electron donor. The presence of tetrathiafulvalene on the NP lowered the surface charge density, reducing the Coulombic repulsion and hence inducing the formation of a continuous metal-like film with excellent reflectivity and mechanical properties. The Au NP assembly can act as an interfacial redox catalyst allowing heterogeneous electron transfer from one phase to another in a much more reversible manner than in the absence of Au NPs [92]. This could be achieved as the Fermi levels are varying with the interfacial potential difference, allowing the control of the electron transfer rate and direction (Figure 3B).

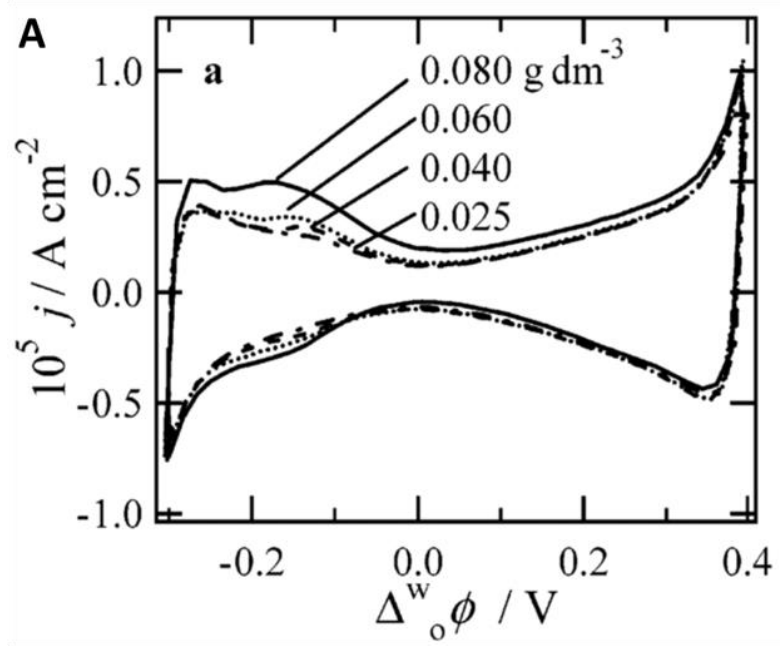

B

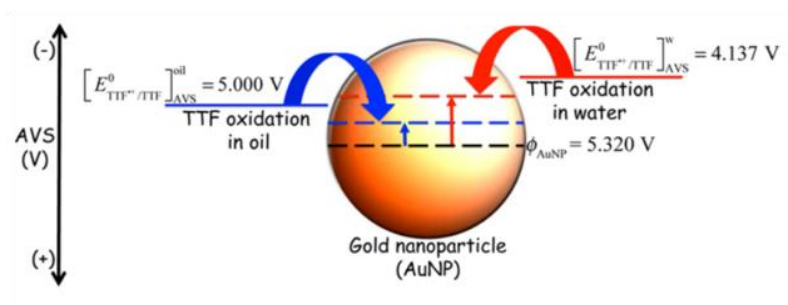

Figure 3. (A) NPs adsorption at the liquid-liquid interface followed by cyclic voltammograms at $100 \mathrm{mV} \mathrm{s}^{-1}$ showing adsorption / desorption of Au NPs observed between -0.2 and $-0.1 \mathrm{~V}$; Adapted from ref. [89] (B) Schematic representation of the work function shift of the Au NPs during charge transfer with tetrathiafulvalene to more reducing potentials. AVS stands for absolute vacuum scale, which corresponds to the scale for the absolute energy positions of the conduction and valence bands, Adapted from ref. [91]

The behaviour of $\mathrm{TiO}_{2}[93,94]$, Au [89,91,92,95-97], and CdSe [98] NPs have already been studied by electrochemistry at the ITIES. 


\subsection{Carbon-based materials}

Carbonaceous materials including single and multi-walled carbon nanotubes (CNT), graphene (GR) or graphite flakes do not disperse well in both the aqueous and the organic phase and like other nanomaterials, under proper conditions, they can assemble at the liquid - liquid interface $[99,100]$. Such carbon nanomaterials can be then used as assemblies floating on the interface improving chemical reaction or electron transfer kinetics thanks to their conductive properties. They were referred as conductive rafts in the literature [101]. Biphasic junctions give an ultimate environment for biocatalytic conversion of water-insoluble chemicals. An enzyme, soybean peroxidase, fixed to single-walled CNT was adsorbed at the water - hexane interface with the help of ionic surfactants [102]. The enzyme catalyzed the electron transfer from $\mathrm{H}_{2} \mathrm{O}_{2}$ present in the aqueous phase to lipophilic $p$-cresol resulting in its oxidation. The presence of CNT scaffolds ensured high accessibility of the catalytic sites for the biphasic reagents resulting in an efficient increase in the reaction rates. Beside high specific surface area that expedites interfacial adsorption, carbon-based materials enrich interfacial region with additional conductive rafts that can facilitate heterogeneous electron transfer reactions. Graphene and mesoporous carbon decorated with $\mathrm{MoS}_{2}$ particles dispersed in the 1,2-DCE catalyze hydrogen evolution reaction (HER) at the ITIES [103]. Carbon supports provided well distributed and monodispersed NPs of affordable $\mathrm{MoS}_{2}$ catalyst and at the same time served as highly conducive bridge for electron transfer between the decamethylferrocene (electron donor) dissolved in the organic phase and catalyst NPs for further reduction of protons. HER rates were 38 times higher for graphene- $\mathrm{MoS}_{2}$ and 171 times higher for mesoporous carbon-MoS 2 than for biphasic reduction of protons in the absence of catalyst. These rates were also significantly higher than with nanocrystalline or exfoliated $\mathrm{MoS}_{2}$ were used on their own. Similar results were obtained for HER catalyzed by multi-walled CNT functionalized with $\mathrm{Mo}_{2} \mathrm{C}$ [101]. HER at the electrified water - 1,2-dichlorobenzene interface catalysed by GR and GR-MoS 2 was also recently reported [104].

Graphene was self-assembled at the ITIES and doped with the Pd or Au NPs [105]. The graphene obtained by chemical vapour deposition (CVD GR) on the copper substrate was covered with a $100 \mathrm{~nm}$ layer of poly(methyl methacrylate) (PMMA). Next, the copper substrate was removed by etching in persulfate solution to yield the PMMA/CVD GR bilayer. Once added to the organic phase (mixture between DCE and 5-nonanone), the PMMA, dissolved and released CVD GR which then spontaneously assembled at the ITIES. Few experimental routes were proposed to functionalized CVD GR with metal NPs, nevertheless all required metal 
precursor in the aqueous phase $\left(\mathrm{PdCl}_{4}^{2-}\right.$ or $\left.\mathrm{AuCl}_{4}^{-}\right)$and electron donor (decamethylferrocene) in the organic phase. Resulting NPs size and size distribution varied from 20 up to $300 \mathrm{~nm}$ depending on experimental protocol employed. ITIES decorated with CNT and exfoliated graphene flakes caused the increase in Faradaic currents related to an interfacial electron transfer reaction between 1,1'-dimethylferrocene dissolved in the organic phase and ferricyanide present in the aqueous phase [106]:

$$
D M F c_{(o r g)}+F e(C N)_{6}^{3-}{ }_{(a q)} \rightleftharpoons D M F C^{+}{ }_{(o r g)}+F e(C N)_{6}^{4-}(a q)
$$

In both scenarios, it was assumed that porous materials enlarge the electroactive surface area of contacting liquid phases. It was also shown that Pd metal NPs can be easily prepared on the carbonaceous material at the ITIES with the spontaneous or potential-controlled heterogeneous electron transfer reaction followed by metal precursor reduction. The size of the particles, depending on the support, oscillated around $10-20 \mathrm{~nm}$ for CNT and $20-40 \mathrm{~nm}$ for graphene flakes.

Another way of looking at carbon nanomaterials is to consider them as interfacial propellants. Visualization of non-uniform potential distribution across the electrified liquid - liquid interface was observed with the self-assembled CNTs as shown on Figure 4A [101]. This was mainly due to the arrangement of the counter electrodes and Luggin capillaries positioned on opposite sides of the cell. As a result, the negative polarization of the interface caused the CNT to condensate on the opposite to counter electrodes side whereas positive polarization caused the CNT to laterally flow toward the region on beneath aqueous phase counter electrode. Beside cell symmetry, also the simple ion transfer reaction of decamethylferrocene caused the CNT to move within the plane of an interface triggering interfacial instabilities expressed as significant forward currents magnification. ITIES formed in a sessile drop decorated with graphite microparticles trigger amplified interfacial $\mathrm{Na}^{+}$ion transfer [107]. This phenomenon was attributed to potential induced orientation and rotation (see Figure 4B) of graphite flakes causing adjacent solution layer mixing followed by an increase of faradic currents. These observations can be directly linked with the electrochemical instability of the electrified liquid - liquid interface observed in the presence of charged surface active species - adequate description is available in the section devoted to molecular assemblies. 
A

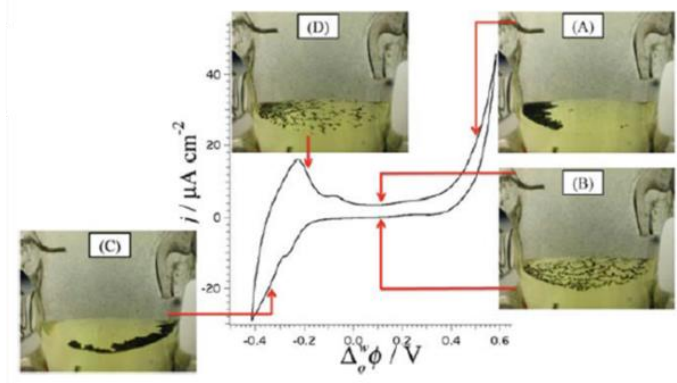

B
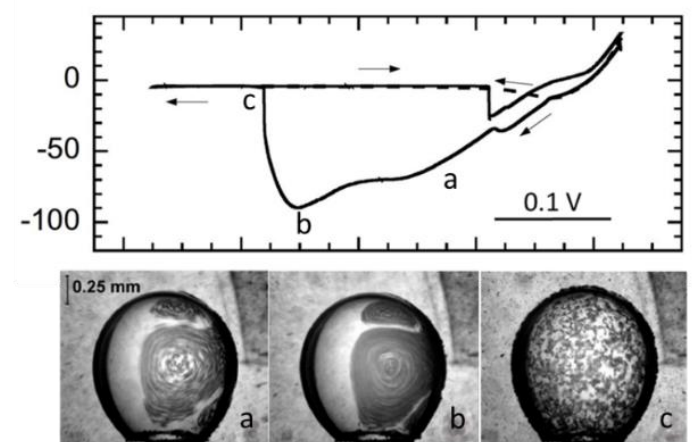

Figure 4. Potential induced movement of carbon based materials self-assembled at waterDCE interface: (A) CNT moving across the liquid - liquid interface plane upon external polarization and ion transfer reaction, adapted from ref. [101], and (B) graphite flakes that rotate and mix the interfacial region causing an increase in Faradaic current of $\mathrm{Na}^{+}$cations transfer. Adapted from ref. [107]

\section{In situ modification}

In situ modification of the interfacial region resulting from the reaction between two or more reagents separated between two adjacent phases based on their lipophilicity can be triggered by external polarization. Electrochemically driven decoration of the ITIES can be accomplished via three main mechanisms: (i) the ion transfer reaction followed by interfacial precipitation, (ii) the ion transfer reaction followed by homogeneous electron transfer reaction or (iii) the heterogeneous electron transfer reaction. Resulting materials (e.g. metal NPs, polymeric films or silicate materials ...) reside at the interface as the requirement to reduce the interfacial free energies needs to be satisfied.

\subsection{Silica materials}

The research on silica electrogenerated at the liquid - liquid interface was achieved through the sol - gel method. Prior to ITIES modification, tetra(alkoxy)silanes typically used as the silica precursor required adequate processing controlled by $\mathrm{pH}$ driven catalysis of two reactions: 
(i)

$$
\text { Hydrolysis: } \mathrm{Si}(\mathrm{OR})_{4}+\mathrm{H}_{2} \mathrm{O} \rightarrow \mathrm{Si}(\mathrm{OR})_{3} \mathrm{OH}+\mathrm{ROH}
$$

(ii)

$$
\text { Condensation: } 2 \mathrm{Si}(\mathrm{OR})_{3} \mathrm{OH} \rightarrow(\mathrm{RO})_{3} \mathrm{Si}-\mathrm{O}-\mathrm{Si}(\mathrm{OR})_{3}
$$

The morphology of resulting silica materials can be additionally controlled via addition of positively charged surfactants (e.g. cethyltrimethylammonium cations $-\mathrm{CTA}^{+}$) at concentrations assuring formation of liquid crystals [108-110]. Electrostatic interactions between positive surface charge of a soft template and negatively charged silica species allows the mutual self-assembly and consequently the formation of a mesoporous solid material (Figure 5). In general, the liquid - liquid interface was used to separate the silica precursor species from the template salt, whereas the potential driven ion transfer reaction allowed the control of a deposition process. This methodology was investigated by two groups $[111,112]$. The liquid junction separates the solution of the soft catalyst and cationic part of the organic electrolyte from the aqueous solution of silica precursors The electrochemically driven transfer of cationic surfactant from the organic to the aqueous phase and successful self-assembly with the silica precursor resulted in interfacial silica film deposition [111,112].

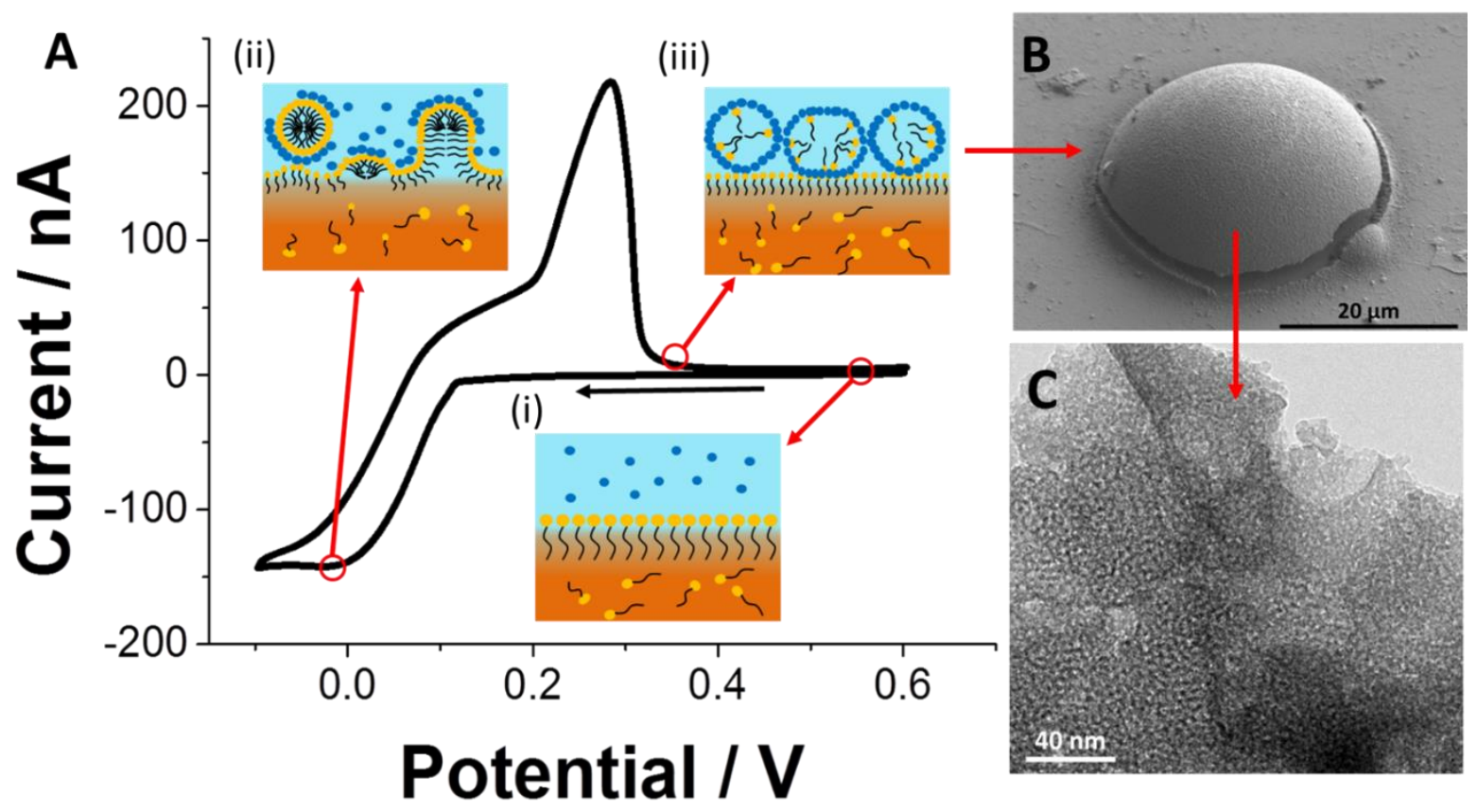

Figure 5. (A) Cyclic voltammogram recorded during silica electrogeneration at the ITIES. Aqueous phase was $50 \mathrm{mM}$ hydrolyzed TEOS and $5 \mathrm{mM} \mathrm{NaCl}$ at $\mathrm{pH} \sim 9.5$; Organic phase was $10 \mathrm{mM} \mathrm{BTPPA}^{+} \mathrm{TPBCl}^{-}$and $14 \mathrm{mM} \mathrm{CTA}^{+} \mathrm{TPBCl}^{-}$; Scan rate was $5 \mathrm{mV} / \mathrm{s}$. Silica formation steps: (i) Beginning of polarization, no ion transfer reaction; (ii) $C T A_{o r g \rightarrow a q}^{+}$followed by selfassembly with the hydrolyzed TEOS species; (iii) interfacial deposition and adsorption of $\mathrm{CTA}^{+}$ 
among silica framework. (B) is the SEM micrograph of silica deposits at the $\mu$ ITIES and (C) is the TEM micrograph indicating wormlike structures. Adapted from ref. [113]

The interfacial silica generation triggered and controlled by electrochemical $C T A_{\text {org }}^{+} \rightarrow a q$ transfer results in a formation of a mesoporous material with pores having so-called 'wormlike' structures (see. Figure 5C). Spectroscopic study revealed that besides soft template also the organic electrolyte ions are present in silica after desorption [114]. It was also found that silica deposits can be stabilized and reused once proper support was employed. Silicon wafers patterned with an array of micro or nano pores each supporting the ITIES were modified as shown on Figure 5B and Figure 6B,D respectively [113,115]. Interestingly, the shape of resulting silica deposits was found to be a print out of the diffusion zones of $\mathrm{CTA}^{+}$on the aqueous site of the liquid - liquid interface. Dome like shapes (see Figure 5B or Figure 6C, D and F) were found for the arrays with spacing between single pores assuring individual hemispherical diffusion regimes. For densely packed pores with overlaying diffusion zones, silica deposit formed a block entirely covering all pores (see Figure 6A, B and E).
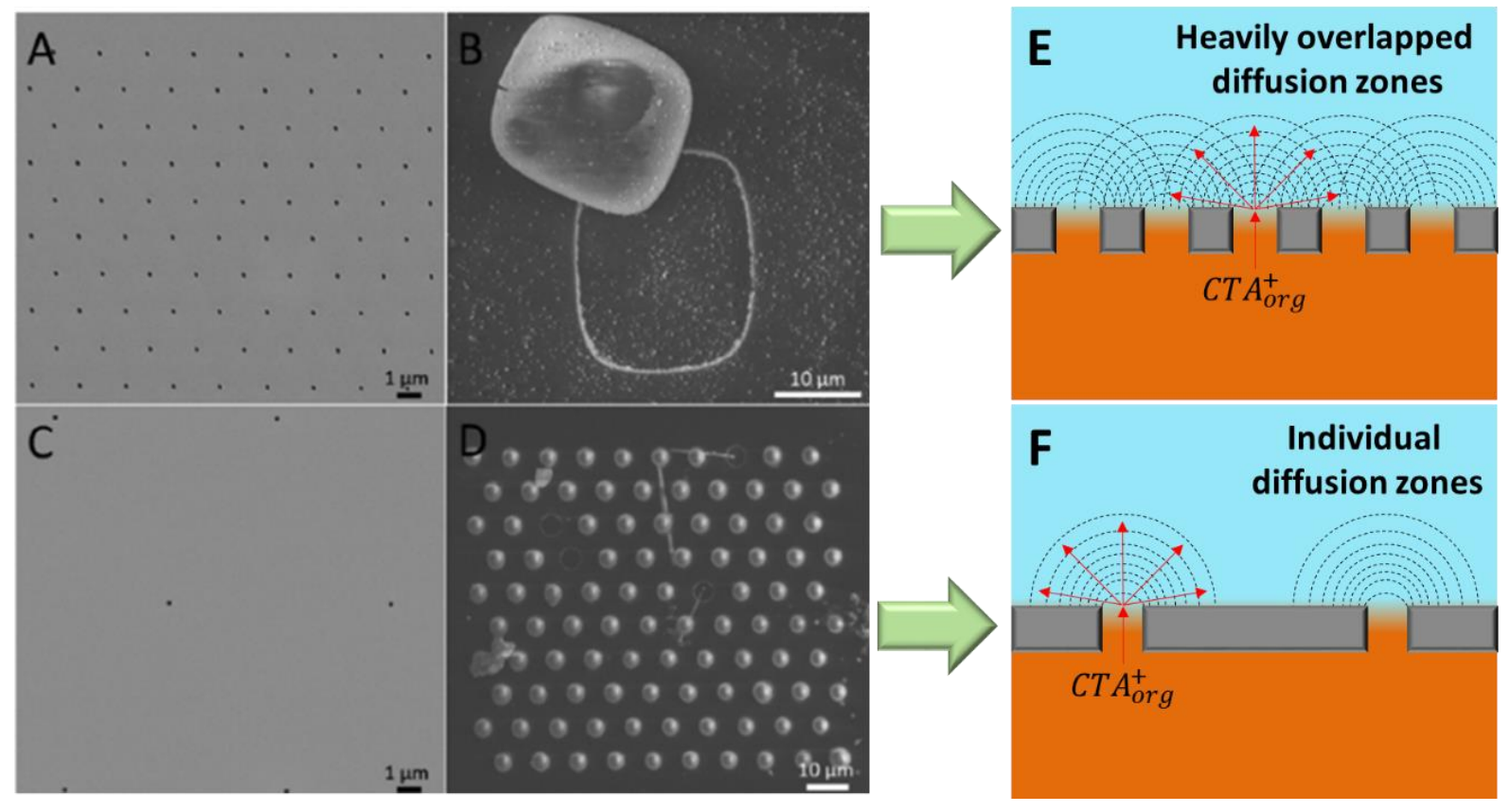

Figure 6. SEM images of the array of nanoITIES before (A and C) and after modification (B and D) with $\mathrm{CTA}^{+}$templated silica. Pores diameter within each array equal to around $90 \mathrm{~nm}$. For the array with low spacing silica deposit in a form of a compact block was electrodeposited and originated from heavily overlapped diffusion zones of $\mathrm{CTA}^{+}$on the aqueous site of the ITIES (scheme E). When spacing between pores was high enough to ensure individual 
hemispherical diffusion zones (scheme F) silica deposits formed dome like shapes above each pore. Adapted from ref. [115].

Due to intrinsic porosity and modular surface chemistry, mesoporous silica materials are widely used in separation process [116-118]. Charge and size sieving properties of a silica modified array of microITIES were investigated in the presence of 4-octylbenzenesulfonic acid (4OBSA ${ }^{-}$ ) and family of quaternary ammonium cations [42]. Change in free Gibbs energy of ion transfer increased in the order $4 \mathrm{OBSA}^{-}>\mathrm{TBA}^{+}>\mathrm{TEA}^{+}>\mathrm{TMA}^{+}$indicating electrostatic repulsion between negatively charged silica pores and anions as well as steric obstacle for positively charged species declining together with their size. The output of ion transfer voltammetry of synthetic dendrimers in the presence of silica deposits (i) gave lower faradaic currents, (ii) required less energy and finally (iii) indicated adsorption process.

One approach dealt with the three phase junction - solid electrode contacted with the liquid liquid interface - modification with the silica material [119]. In this study, electrochemically controlled oxidation of sulphites dissolved in the aqueous phase has led to the $\mathrm{pH}$ decrease, catalysing the hydrolysis and further condensation of the n-octyltriethoxysilane being dissolved in contacting nitrobenzene. Resulting silica stripe was deposited at the solid electrode, almost completely on the aqueous side of the liquid - liquid junction. Electrochemically controlled local $\mathrm{pH}$ gradients can serve as a straightforward method to trigger mesoporous silica deposition, even with the high structural order, over conductive supports [109]. By analogy, it was recently proved that local $\mathrm{pH}$ change at the electrified liquid - liquid interface can also be used for ITIES decoration with silica film [120]. Instead of electrons directly available from the solid electrodes, trimethylbenzhydrylammonium cation dissolved in the organic phase was first transferred to the aqueous phase where upon photoirradiation it decomposes forming reactive radical carbocation and trimethylamine. $\mathrm{pH}$ drop close to the interfacial region initiated sequence of reaction: (i) hydrolysis of TEOS present in the organic phase, (ii) partition of resulting silanols to the aqueous phase, (iii) self-assembly together with $\mathrm{CTA}^{+}$used as a soft template and finally (iv) condensation and interfacial deposition.

Silica-Pt hybrid deposit could be form through charge transfer at the ITIES. Interfacial deposition was controlled by simple ion transfer of $\mathrm{TODA}^{+}$from the organic phase to the aqueous phase containing $\left(\mathrm{NH}_{4}\right)_{2} \mathrm{PtCl}_{4}$, and water glass solution being a silica precursor [121]. Since the reaction was controlled by electrochemical transfer of charged surfactant species that can act as a soft template, the resulting silica deposits could have interesting structural 
properties. Furthermore, the reduction of metal precursor is expected to form metal NPs distributed within inorganic and probably porous silica framework. We anticipate that such a hybrid material could find interesting applications in the field of e.g. catalysis, separation, adsorption or sensing. The properties of interfacially formed silica deposit could be even further tuned with range of metallic NPs as these can be easily formed at the electrified liquid - liquid interface.

\subsection{Metal nanoparticles}

Deposition of metallic NPs at the ITIES can be achieved through the reduction of an aqueous metallic salts by a suitable reducing agent dissolved in the organic phase. This reduction may be conducted by controlling the electron transfer between the redox couples, i.e. (i) homogeneous ET preceded by phase transfer of metal ion precursors or by (ii) heterogeneous electron transfer taking place at the liquid - liquid interface. The first report of "in situ metallization" of liquid - liquid interfaces was performed by Guainazzi et al. in 1975 who reported the reduction of $\mathrm{Cu}^{2+}$ ions by a reducing agent (vanadium hexacarbonyl) followed by metallic $\mathrm{Cu}$ deposition at the electrified interface [122]. The rate of metal deposition was controlled by the potential difference established across the interface, considered as the reaction driving force. Although the electrodeposition process at soft interfaces has some similarities with heterogeneous nucleation of particles at solid - liquid interfaces, the actual potential of a growing particle at the soft junction remains unclear. For a metal $\mid$ solution interface, this problem can be easily defined since the potential experienced by the new growing phase is that of the electrode, therefore the growth overpotential will be defined. However, a liquid - liquid interface would be considered as a dielectric termination rather than a conductor, thus once the nucleation process is taking place, the interaction between the newly formed metallic phase and the liquid - liquid interface will be very small and the growth overpotential may occur on isolated sites. This lack of interactions might facilitate a direct analysis of the new growing metallic phase in a unique environment - free from preferential nucleation sites - to observe and study the relationship between the driving force of growth and shape of the resulting particles. In the mid-90s, systematic studies of electrodeposition of metallic Au clusters at the water-DCE interface were carried out [123]. Following works investigated potentiostatic and galvanostatic deposition of Pd NPs at liquid - liquid interface were supported by theoretical models assuming (i) diffusion controlled nucleation and (ii) the importance of agglomerates formation on the growth kinetics of NPs [124-126]. 
The absence of solid substrate at liquid - liquid interfaces means that deposited NPs can undergo lateral displacement upon interfacial polarization and interfacial tension gradients and therefore form agglomerates [127,128]. Analysis of the shape-driving force relationship might be inaccurate in the case of macro-interfaces. A controlled deposition of Pd NPs on $\gamma$-alumina membranes with a pore diameter of 20 and $100 \mathrm{~nm}$ was then carried out (see Figure 7A) to control the size of the deposited NPs [124,129-131]. Despite the confined interfacial area within the alumina pores, metallic NPs grew as small non-uniform aggregates rather than single, well dispersed NPs. For instance, $\gamma$-alumina templated deposits of Pd and Pt NPs gave rise to small $(<10 \mathrm{~nm}$ diameter) aggregates of particles for both metals [131]. $\mathrm{Ag}, \mathrm{Au}$, and $\mathrm{Pt}$ nanoelectrodes were then produced by in situ interfacial reactions at a liquid - liquid interface supported by non-silanized nanopipettes [132]. Explanations for a possible apparent autocatalytic growth have been proposed where either (i) the nucleation of a particle can be triggered by the presence of an initial particle, leading to non-uniform particle distribution, or (ii) the nascent metal particle would be able to conduct electrons, thus the coupled diffusion zones effectively extend over larger distances, i.e. larger zones of solution would be reached [127,131]. Both explanations might be supported by the appearance of nucleation loops recorded by cyclic voltammetry during NPs deposition, which are an indicator of an accelerated process [124,125,127,129-131,133,134]. Nevertheless, the presence of impurities at the ITIES could act as preferential nucleation sites for growing NPs [135].

Successive queries pertain to electrodeposited NPs and the ET mechanisms taking place at the liquid - liquid interface: (i) Is the ET heterogeneous or homogeneous? (ii) Which intermediates governs the reaction and the rate of electrodeposition? The earliest reports clearly depicting a mechanism of gold NPs synthesis at the ITIES have been related to the Brust-Schiffirn route [136-142], although this method is not electrochemically driven. On the other hand, mechanistic aspects of Au electrodeposition at the liquid - liquid interface were investigated [134]. Although very informative, the cyclic voltammograms were not clear enough to determine if $\left[\mathrm{AuCl}_{2}\right]^{-}$species are intermediates during the formation of Au NPs. This is because metallic precursor anions, $\left[\mathrm{AuCl}_{4}\right]^{-}$and $\left[\mathrm{AuCl}_{2}\right]^{-}$, gave similar charge transfer voltammograms (i.e. similar behaviour for IT and ET) [134]. The presence of $\left[\mathrm{AuCl}_{2}\right]^{-}$species as an intermediate when $\left[\mathrm{AuCl}_{4}\right]^{-}$is reduced with tri-p-tolylamine (TPTA) at the water - DCE interface was confirmed [143]. Coupled in situ X-ray fluorescence (XRF) and X-ray absorption fine structure (XAFS) techniques monitored the gold nucleation and NPs growth at an electrified interface, which supported the formation of spherical gold NPs aggregates described by ex situ studies 
reported in earlier publications (see Figure 7B) [142]. Furthermore, in-situ XAFS was used to describe the growth and deposition of Pd NPs suggesting a direct two electron reduction of $\left[\mathrm{PdCl}_{4}\right]^{2-}$ to $\mathrm{Pd}^{0}$ followed by the formation of stable Pd clusters [144]. Certainly, a better understanding of the NPs growth dynamics at a molecular scale during the interfacial electrodeposition is desirable. We anticipate that further development and mechanistic aspects related to NPs formation requires molecular insight from interfacial region. These can be achieved by in situ coupling of spectroscopic techniques (e.g. X-ray scattering, Raman, Fluorescence, UV-vis among others) with electrochemistry at liquid - liquid interface.

Aside from theoretical studies which suggest a liquid - liquid interface as the ideal environment to study nucleation and growth of metallic NPs, the control of their size, morphology and composition can be considered as another challenge. The size of gold NPs co-deposited in a polymeric matrix can be varied (between $20-30 \mathrm{~nm}$ ) by the modification of the Galvani potential difference established at the water-DCE interface [145]. The equilibrium potential controlled with the common ion approach (with the help of different partitioning ions e.g. $\mathrm{TPrA}^{+}, \mathrm{TMA}^{+}$, $\mathrm{Cs}^{+} \mathrm{Li}^{+}$and $\mathrm{K}^{+}$) allowed the control of aqueous concentration of the gold complex initially present in the organic phase. Simple ion transfer of the gold complex from the organic to the aqueous phase was followed by a homogeneous reduction by the monomer (e.g. tyramine, resorcinol) resulting in the formation of gold NPs co-deposited in a polymeric matrix. The size of the synthesised NPs increased with the increasing Galvani potential. More recent studies on the interfacial electrodeposition of Au did not establish a clear correlation between the size of the particles and the applied potential difference claiming that it is rather the number of NPs that can be controlled with the energy supplied from external polarization [134]. Similar findings were proposed by Platt et al. [133], wherein the formation of small Pd and Pt clusters may follow a foreseeable set of arrangements similarly to the so-called full-shell clusters where small clusters of atoms tends to arrange themselves to form complete closed shells [146].

Long and well-defined silver nanofibers and nanowires networks were deposited by a reaction at the liquid - liquid interface between silver nitrate dissolved in the aqueous phase and reducing agent (e.g. ferrocene, decamethylferrocene) present in the organic solvent [145,147,148]. Different morphologies are obtained by choosing the appropriate concentrations of reactants for each phase. For instance, it is possible to get either the growth of silver wires (a.k.a. whiskers), Christmas tree-like, or extremely smooth films of silver. Core-shell-like structures with metallic co-deposits of Pd@Pt and Cu@Au (Figure 7C) were reported, pointing out a new route toward the preparation of uniform and monoatomic shells on noble metals 
[133,149]. Recent studies on heterogeneous electron transfer between metal complex ions dissolved in the aqueous phase and reducing agents dissolved in ionic liquids have received increased attention $[150,151]$. Novel metal nanostructures of gold such as dendritic nanofibers, nanorods or worm-like nanowires have been synthesized, meaning that electrified water - ionic liquid interface can lead to the synthesis of a wide record of new nanostructures.

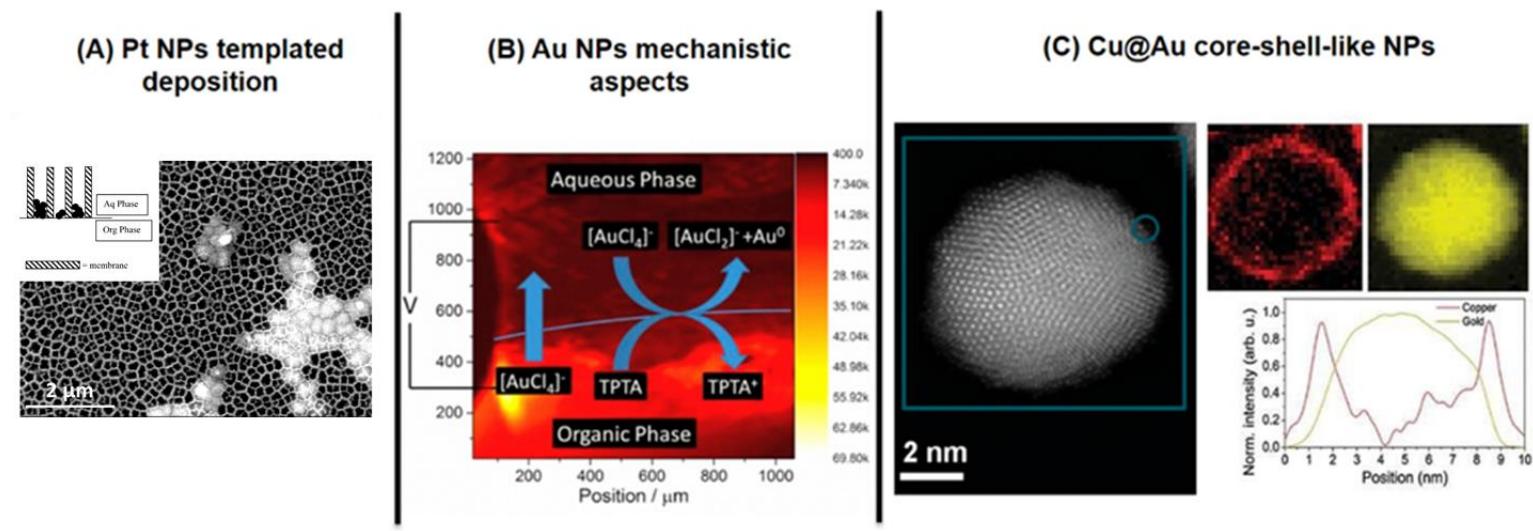

Figure 7. Different approaches on interfacial deposition of metallic NPs at an electrified liquid - liquid interface; (A) - Controlled deposition of Pt NPs within $\gamma$-alumina membranes with a pore diameter of $100 \mathrm{~nm}$; (B) XRF mapping depicting the mechanism for the reduction of $\left[\mathrm{AuCl}_{4}\right]^{-}$with TPTA; (C) - Electrosynthesis of core-shell-like structures of $\mathrm{Cu} @ \mathrm{Au}$. Adapted from: (A) refs. [129,133], (B) ref. [142]; and (C) ref. [149].

\subsection{Organic polymers}

Interfacial electropolymerization of organic molecules undergoes through ET between redox couples separated by the liquid - liquid interface. In most cases, ET leads to the formation of radical cations of monomeric species which subsequently react with each other forming dimers, trimers, oligomers and finally polymers that precipitate at the liquid - liquid interface. The polymerization rates will depend on reactive ionic species solubility in each phase and if the ET is homogeneous or heterogeneous. The first report regarding electrochemical interfacial polymerization was carried out by Cunnane et al. who studied the formation of 1-methyl and 1-phenyl pyrrole oligomers, however no interfacial deposits were observed [152]. Interfacial electropolymerization of $2,2^{\prime}: 5^{\prime}, 2^{\prime}$ ''-terthiophene undergoes mechanism similar to that at the metal electrode/electrolyte interface [153]. The polymerization initiated by the electron transfer between cerium (IV) dissolved in the aqueous phase and terthiophene dissolved in the organic phase was studied by chronopotentiometry and impedance spectroscopy. On the chronopotentiograms, the potential increased rapidly, corresponding to electropolymerisation 
of the terthiophene molecules in the vicinity of the interface. Polymerisation rate slowed down as the interface is a mixed solvent layer [154] and thereby, terthiophene diffusion slows down with the presence of water [153]. These studies suggested that the rate of polymerization at liquid liquid interfaces would be controlled by diffusion rather than electron transfer. The heterogeneous ET between Ce (IV) and terthiophene followed by polymerization was monitored by UV-Vis spectroscopy allowing the identification of different thiophene oligomeric species for various interfacial potentials and terthiophene concentrations [155]. Attempts on describing the nucleation growth and the electrochemical switching (dopingundoping states) of polyterthiophene at the liquid - liquid interface have been reported $[156,157]$.

Polymeric layers of 4-(pyrrol-1-yl)phenyloxyacetic acid at the water - DCE interface were synthesized although no ET process was recorded [158]. The formed polymeric film inhibited the transfer of $T M A^{+}$and $P F_{6}^{-}$indicating that the deposit acted as a mechanical obstacle rather than a charged electrostatic barrier. Similar studies were carried out with two polypyrrole derivatives, poly-4-[bis(pyrrol-1-1-yl)methyl]-phenyloxyacetid acid and poly-4-\{4-[bis(pyrrol1-yl)methyl]-phenyiloxy \}-butanoic acid (see Figure 8A) [159]. These polymers were deposited as result of the oxidation of the corresponding monomer with ferric ions, followed by its oligomerization and subsequently polymerization. High compactness of the polymeric films was found to inhibit the permeability of small ions such as potassium and protons. The addition of a surface active derivative of cyclodextrin (tert-butyl- $\gamma$-cyclodextrin) during the polymerization process increased the permeability of the polymer as proved via ion transfer voltammetry. Polymerization by reduction reactions can also take place at an electrified interface. For instance, arenediazonium ions were transferred and the reduction by decamethylferrocene lead to an irreversible dediazonation, giving arene radicals, which promoted the radical polymerization of styrene at the interface [160]. The film of polystyrene formed also inhibited the transfer of ions across the interface.

Examples of the ITIES decorated with hybrid polymer/nanomaterial include (i) metallic NPs embedded in a polymer matrix or (ii) carbon based materials covered with polymeric film. Polyphenylpyrrole-coated silver particles at a liquid - liquid interface were synthesised with s the slow homogeneous electron transfer between N-phenylpyrrole and the silver ions, as ratelimiting step, followed by polymerization and metal cluster growth [161]. Simultaneous nucleation of gold NPs and polymerization of tyramine at the water - DCE interface were studied [145,162,163]. A fast homogeneous electron transfer between tyramine and gold ions was followed by the tyramine polymerization and gold NPs deposition. Carbon based materials 
were used to control interfacial polymerization of polypyrrole on SWCNT assembled at the interface (see Figure 8B) [164]. These free-standing SWCNT/polypyrrole composite layers were transferable to solid substrates, thus enabling the fabrication of novel functional electrodes [165].

Synthesis of conductive polymers can also be performed at the three phase junction systems [166-172]. Controlled electrochemical oxidation of monomers (e.g. 3,4ethylenedioxythiophene, pyrrole, aniline, $\mathrm{N}$-vinylcarbazole,etc) dissolved in the organic phase at the metallic working electrode allowed the formation of polymeric films growing laterally over the liquid - liquid interface (see Figure 8C). Radial frontier of the formed film acted as an electroactive active nucleation site resulting in polymeric films holding Janus properties (different morphologies on both sides). Despite the easiness of the approach the variety of nanostructures synthesized at three phase junction are still quite limited. Liquid-liquid interfacial polymerization is considered as a prominent method to grow polymers with outstanding characteristics (e.g. low dimensionality, uniform size distribution, high crystallinity and improved physical properties but it is only limited to the production of bulk polymers and polymeric nanocomposites [173-176]. So far, little attention has been paid to the controlled growth of polymers at the electrified liquid - liquid interface. New frontiers and features in morphology and conductivity have been reached working under steady or dynamic Galvani potentials (accelerating or inhibiting the polymerization process). Synthesis of polymeric materials in a form of ultrathin nanowires, nanofibers or single crystal nano-needles reported in literature at solid - liquid interface and at non-polarized liquid - liquid interfaces [173,177180] might be reproduced and accelerated under specific conditions at an electrified soft interface. To achieve this goal, fundamental understanding of nucleation, polymer growth with a complete electrochemical characterization (e.g. doping-undoping, conformational relaxation behavior, capacitive contributions, etc) at an electrified interface is required. We are convinced that further effort can open up new avenues in the field. 


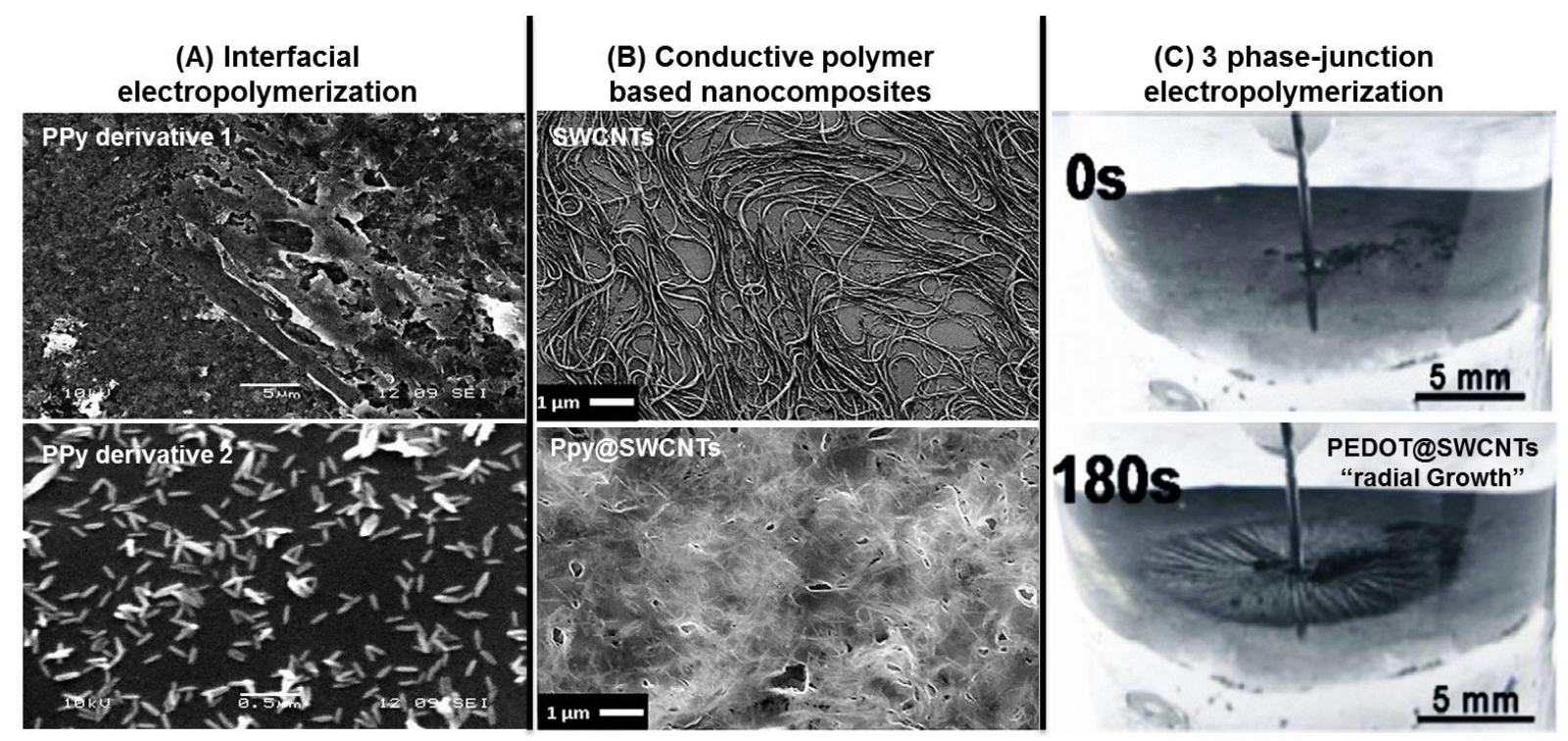

Figure 8. Different approaches on interfacial electropolymerization A - PPy synthesized at an electrified interface from two different type of pyrrole monomers: B- electropolymerization of PPy over SWCNTs assembled at the liquid - liquid interface; C - Electrosynthesis of PEDOT@SWCNT composites by 3-phase junction method. Figures adapted from: (A) ref.[159]; (B) ref. [164]; and (C) ref. [171]

\section{Ex-situ modification}

The modifiers that are prepared prior to ITIES decoration are essentially membranes holding desired properties. Specific design together with adjusted surface chemistry allows the control of the ITIES position within the support whereas the morphological characteristics are usually adjusted in a way that affects the interfacial transfer reactions in a defined manner. Up to now, such materials were mainly used in electroanalysis.

\subsection{Nano-ITIES}

Inspired by ion transport in nature, the control of mass transfer through arrays of solid-state nanopores (typically with a diameter ranging from 10 to $200 \mathrm{~nm}$ ) has been investigated at the liquid - liquid interface [181,182]. The preparation of arrays of nano-interfaces has been achieved by either electron beam lithography [183] or by focused ion beam milling [184] through silicon nitride membranes (50-100 nm thick). Mass transport over such nano-arrays is improved resulting in an increase of sensitivity per unit area compared to interfaces in the micron or centimetre scale [185]. Despite this improvement, the signal measured at such nanoarrays was only half of the value expected for such devices [186,187]. This discrepancy between experimental observations and theoretical calculations were due to the overlap of the diffusion 
zones for densely packed nano-interfaces (see Figure 9A), while widely spread interfaces showed independent diffusion profiles (see Figure 9B) [115]. By increasing the ratio pore-topore separation (S) / pore radius (r), the sensitivity increased and limits of detection improved until they reach a plateau for ratio values greater than 56 [188]; leading to the detection of 0.8 $\mu \mathrm{M}$ of propranolol using a moderately sensitive technique such as linear sweep voltammetry [189].
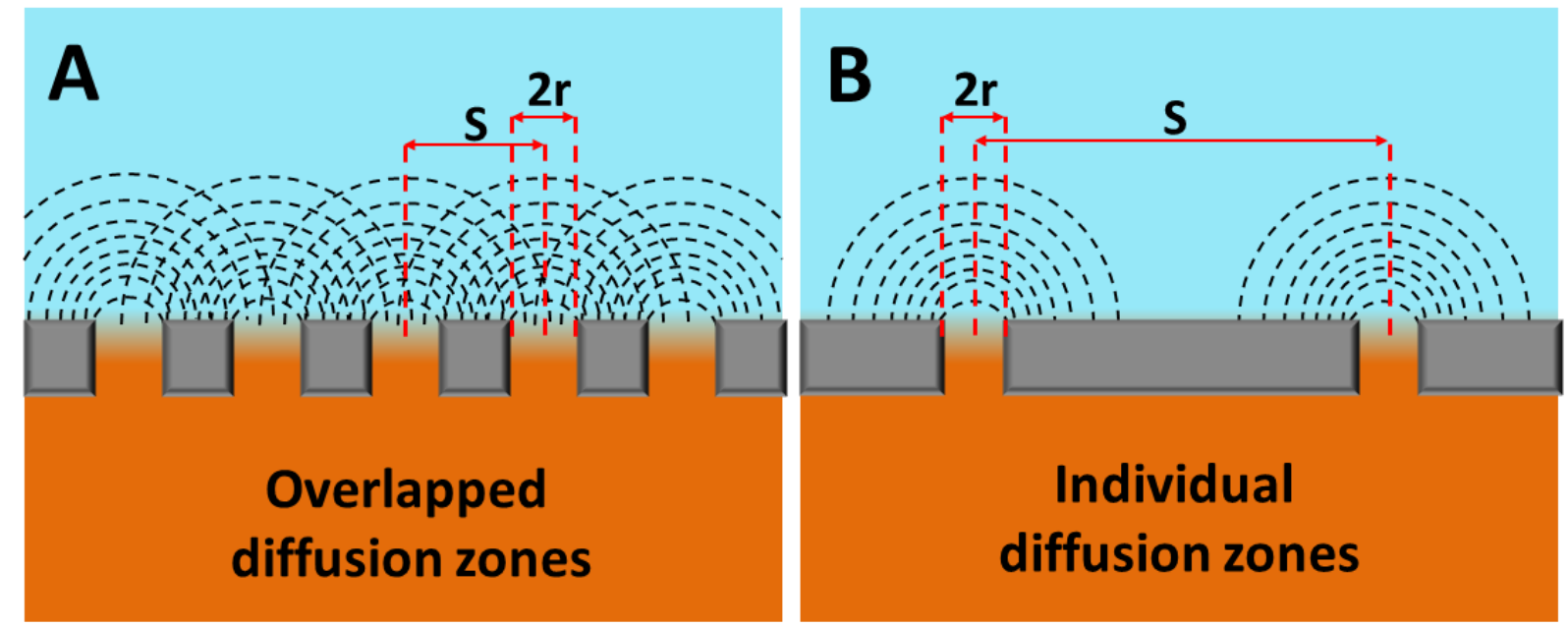

Figure 9. Representation of array of nano pores with (A) low and (B) high pore centre to centre distance representing overlaid and individual diffusion regimes respectively. S stands for pore to pore separation whereas $r$ is the pore radius.

\subsection{Zeolite and Silica based materials}

Non-polar zeolite membrane was initially prepared at the mercury surface and after proper processing was used to support the ITIES (Figure 10A) [190]. The size of the pores within the zeolite framework allowed the size-selective ion transfer across the interface: transfer of tetraethylammonium cation $\left(\mathrm{TEA}^{+}\right)$was suppressed, whereas the transfer of the smaller tetramethylammonium cation $\left(\mathrm{TMA}^{+}\right)$only encountered partial loss of reversibility. In the second approach, it was shown that the zeolite membrane modified ITIES can significantly increase the potential window [191]. The key requirement was the use of a potential window limiting ions with the size exceeding the zeolite pores. As shown on Figure 10C this was achieved with tetrabutylammonium and tetraphenylborate $\left(\mathrm{TBA}^{+} \mathrm{TPB}^{-}\right)$for which interfacial transfer was suppressed in the presence of zeolite membrane and as a consequence potential window was enlarged until the transfer of aqueous phase electrolyte ions. The size selectivity of the zeolite membrane was completed with charge selectivity [192]. In that case, the ITIES was held in a membrane made out of sodium zeolite-Y healed with tetraethoxy silane. 
Voltammetric results shown reversible transfer of $\mathrm{TEA}^{+}$and size exclusion of $\mathrm{TBA}^{+}$. When negatively charged ions with the hydrodynamic radius smaller than the radius of pores entrance were used $\left(\mathrm{BF}_{4}^{-}\right.$and $\left.\mathrm{ClO}_{4}^{-}\right)$no ion transfer was recorded (see Figure 10D) resulting from electrostatic repulsion with negatively charged silica. Besides forming an obstacle, the presence of porous material affected ionic currents characteristics. Diffusion coefficients of $\mathrm{TEA}^{+}$ measured within zeolite membrane were found in the range from 1.9 to $3.8 \times 10^{-8} \mathrm{~cm}^{2} \mathrm{~s}^{-1}$, which is two order of magnitude lower than corresponding bulk value of $10 \times 10^{-6} \mathrm{~cm}^{2} \mathrm{~s}^{-1}$ [193]. Another application of sodium Zeolite Y placed at or near the electrified liquid - liquid interface was to exchange proton with sodium. This was achieved by electrochemical extraction of sodium ions facilitated by dibenzo[18]crown-6 ionophore present in the 1,2-DCE that were afterwards replaced by $\mathrm{H}^{+}$[194].

Porous polyethylene terephthalate (PET) membrane were modified with mesoporous silica via aspiration induced infiltration method which is a modification of soft templated sol - gel process performed under acidic conditions [195]. Resulting silica mesopores were found to grow along the preformed macropores of a PET membrane as depicted on Figure 10B. This $e x$ situ silica modified membrane supported the ITIES and was used to study the ion transfer of $\mathrm{TEA}^{+}, \mathrm{K}^{+}$and of organic anion assisted by cytochrome c. Among all three studied species only the ion transfer associated with cytochrome $\mathrm{c}$ was suppressed as the average silica mesopore diameter was estimated to be $3 \mathrm{~nm}$ which is enough for macromolecular sieving. A membrane modified in a similar manner was used as a liquid - liquid based electrochemical sensor for the folic acid detection [196].

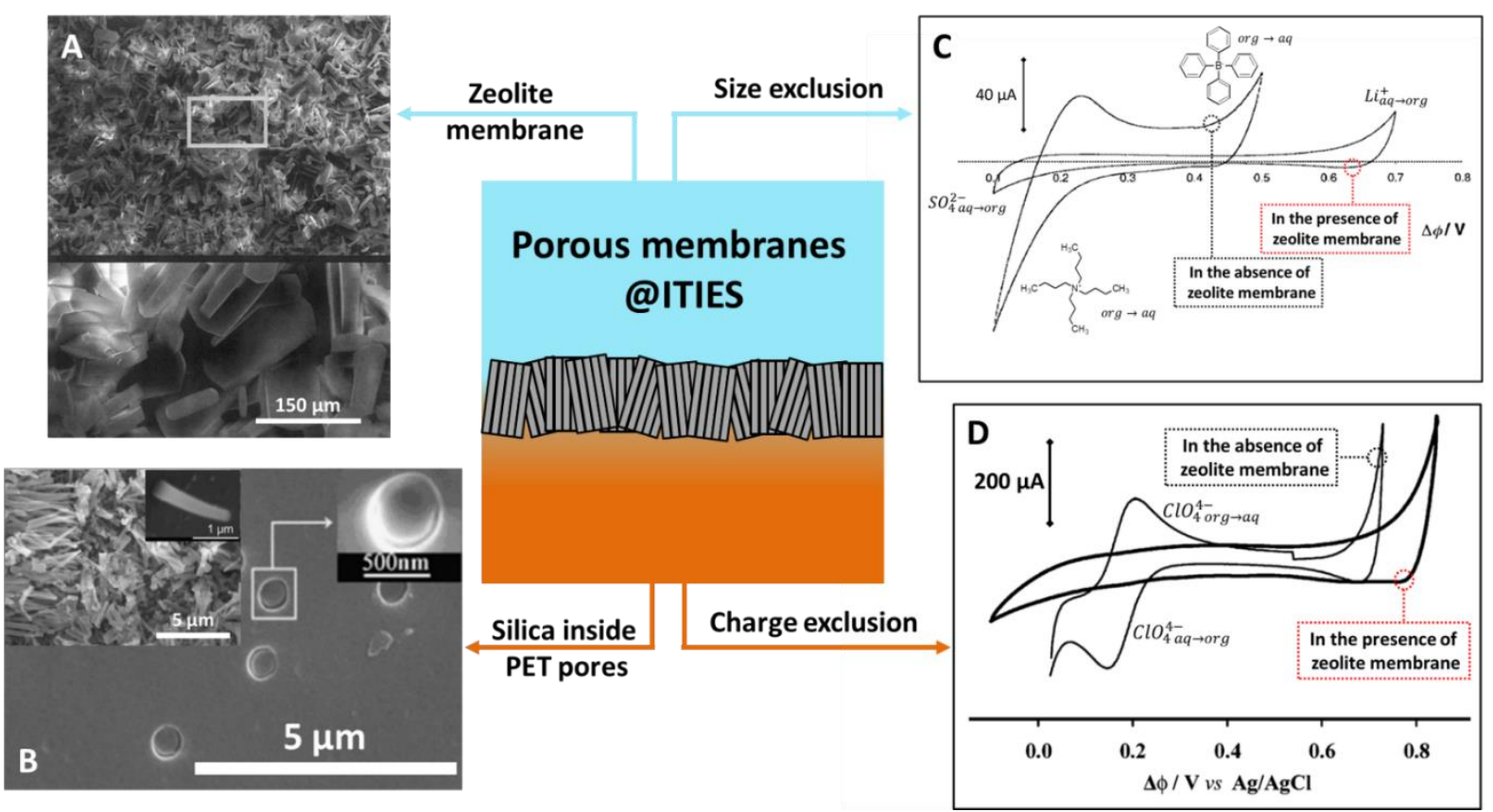


Figure 10. Examples of an ex situ prepared membrane: (A) SEM images of a silicate membrane grown on a mercury surface (Adapted from ref. [190] and (B) SEM image of pores within polyethylene terephthalate (PET) membrane filled with mesoporous silica (Adapted from [195]). Cyclic voltammograms on part (C) show the effect of zeolite membrane on potential window recorded in the absence and in the presence of zeolite membrane. The aqueous phase electrolyte was $100 \mathrm{mM} \mathrm{Li}_{2} \mathrm{SO}_{4}$, the organic phase electrolyte was $20 \mathrm{mM} \mathrm{TBA}^{+} \mathrm{TPB}^{-}$and the scan rate was $50 \mathrm{mV} \mathrm{s}^{-1}$ (Adapted from ref. [191]). Charge exclusion of $\mathrm{ClO}_{4}^{-}$ion transfer via a zeolite membrane impregnated with tetraethoxysilane are depicted on part $\mathrm{D}$. The $\left[\mathrm{ClO}_{4}^{-}\right]=5$ $\mathrm{mM}$ and the scan rate was equal to $20 \mathrm{mV} \mathrm{s}^{-1}$ (Adapted from ref. [197]).

Ex-situ prepared silica isoporous film supported on micropatterned SiN-coated silicon wafers were used to study ion transfer reactions across electrified water - DCE interface [198-200]. Sigmoidal shape of the forward and the reversed voltammetric ion transfer signals indicated that mass transfer of species from both sites of the interface is governed by hemispherical diffusion. Nanopores of the membrane allowed the control of the ion transfer reaction via: (i) varying the $\mathrm{pH}$ of the aqueous phase and corresponding deprotonation/protonation of silanol functionalities inside the pore; (ii) varying the aqueous phase background electrolyte concentration that affects the thickness of the electric double layer and cause pore surface charge to be screened; (iii) size exclusion of a macromolecules resulting from $2-3 \mathrm{~nm}$ wide pore diameters and (iv) incorporation of charged functionalities into silica pores with the help of silane-based post-modification treatment.

\section{Applications}

\subsection{Redox catalysis}

One of the existing application arising from the biphasic nature of the liquid - liquid interface is the ability to catalyze reactions between reactants separated based on their lipophilicity [201203]. Placing catalytic nanomaterials at the ITIES can diminish the activation energy supplied in a form of Galvani potential difference or solar irradiation, or both, needed for heterogenous electron transfer reactions. The choice of catalytic nanomaterials at the ITIES is not surprising as (i) they assure large dispersion and exposure of catalytic active sites; (ii) possess high specific surface area and (iii) in some cases enriches interfacial region in conductive rafts. As shown in Table 1, vast amount of effort dealing with catalysis at the ITIES was directed towards oxygen reduction reactions (ORR) and hydrogen evolution reactions (HER). In liquid - liquid interface 
configuration, both ORR and HER involve (i) metallocene as electron donors dissolved in the organic phase, (ii) proton or oxygen available from the aqueous phase that needs to diffuse toward the interface or partition to the organic phase and finally (iii) catalyst that is situated at the ITIES.

Table 1. Some examples of the catalyst nanomaterials that were used to decorate electrified liquid - liquid interface. The biphasic redox reaction together with the nature of the organic phase are also given.

\begin{tabular}{|c|c|c|c|c|}
\hline Catalyst & $\begin{array}{l}\text { Electron } \\
\text { donor* }\end{array}$ & Reduction reaction & Organic phase & References \\
\hline $\mathrm{MoS}_{2}$ & $D M F C$ & $H E R$ & DCE & {$[103,104]$} \\
\hline MoS $_{2 \text {-carbon composite }}$ & $D M F C$ & & DCE & {$[103]$} \\
\hline CNT & $D M F C$ & $H E R$ & DCE & [101] \\
\hline $\mathrm{Mo}_{2} \mathrm{C}$ & $D M F C$ & $H E R$ & DCE & [101] \\
\hline $\mathrm{CNT}-\mathrm{Mo}_{2} \mathrm{C}$ & $D M F C$ & $H E R$ & DCE & [101] \\
\hline $\mathrm{WS}_{2}$ & $D M F C$ & $H E R$ & DCB & [104] \\
\hline GR & $D M F C$ & $H E R$ & DCB & [104] \\
\hline $\mathrm{Pt}$ & $D M F C$ & $H E R$ & DCE & [204] \\
\hline $\mathrm{Pd}$ & $D M F C$ & $H E R$ & DCE & [204] \\
\hline $\mathrm{BiVO}_{4} *$ & $\begin{array}{l}\mathrm{H}_{2} \mathrm{O}-4 e^{-} \\
\rightarrow 4 \mathrm{H}^{+}+\mathrm{O}_{2}\end{array}$ & $\begin{array}{l}{\left[\mathrm{Co}(\text { bpy })_{3}\right]^{3+}+e^{-}} \\
\rightarrow\left[\mathrm{Co}(b p y)_{3}\right]^{2+}\end{array}$ & Butyronitrile & [205] \\
\hline CoAP & $F C$ & $O E R$ & DCE & [78] \\
\hline $\mathrm{Au}$ & $D i M F c$ & \multirow[t]{2}{*}{$O E R$} & DCB & [206] \\
\hline $\mathrm{Au}-\mathrm{Pd}$ & $D i M F C$ & & DCB & [206] \\
\hline Porphyrins & $F C$ & OER & DCE & [207] \\
\hline
\end{tabular}

DCE - 1,2-dichloroethane, DCB - 1,2-dichlorobenzene, GR - graphene, CNT - carbon nanotubes $\left[\mathbf{C o}(\text { bpy })_{3}\right]^{2+3+}$ - cobalt bipyridine, DMFc - decamethylferrocene, Fc - Feroccene, DiMFc - 1,1'dimethylferoccene, CoAP - (2,8,13,17-tetraethyl-3,7,12,18-tetramethyl-5-p-amino- phenylporphyrin) cobalt(II),

${ }^{*} \mathrm{BiVO}_{4}$ catalysed oxygen evolution reaction hence the water oxidation reaction is given.

\subsection{Electroanalysis}

The sensitivity of ion sensing at the ITIES can be improved by several order of magnitudes by downsizing the dimensions of the interface, analogously to electrochemical sensors based on solid electrodes [208-210]. Indeed, when the dimension of the interface is smaller than the diffusion layer thickness (typically a few tens of microns), mass transfer is greatly improved by the shift from a linear to a radial diffusion profile. Fabricated arrays of micro and nanointerfaces have been developed to harness the benefits of greater mass transport to the sensitivity improvement of ion detection at the ITIES [183-189,208-210]. If the transition of macro-ITIES to its micron size counterpart has improved the limits of detection of one or two orders of magnitude, pushing further the limits of detection by reducing the physical dimension of liquid-liquid interfaces down to the nanometre scale has proven difficult to achieve [189]. Individual diffusion profiles for each nano-interfaces were not reached in the timescale of the 
voltammetry experiments, when a centre-to-centre separation of 20 times the radius between two adjacent nano-interfaces were used [189]. The separation had to be increased to more than 50 times the radius to observe independent diffusion profiles, reaching a limit of detection in the range of $80 \mathrm{nM}$ with linear sweep voltammetry [188].

The issue of selectivity could also be overcome by the chemical functionalisation of the liquidliquid interface using the different strategies described in the previous pages. The separation of ionic species at the liquid - liquid interface is governed by their inherent lipophilicity which affects the partitioning between two containing phases. At the electrified liquid - liquid interface the ion transfer reaction can be controlled by Galvani potential difference. The amount of energy needed to be delivered in order to transfer the ion from one phase to another is dependent from its lipophilicity/phobicity. This relation is observable for the family of quaternary ammonium cations, as different substituents can very much affect the energetics of the ion transfer reaction [211,212]. Selective separation of the charged molecules at the electrified liquid - liquid interface can be improved via interfacial modification. This can be achieved with inorganic materials in a form of a membrane e.g. mesoporous silica $[42,196,198,199]$ or zeolite $[190,192]$ materials that can affect size and charge screening properties of the ITIES. For the former the ionic transport is affected by the confined size of the pores within the membrane framework whereas for the latter it is the membrane surface charge governed by ionisable functionalities that can electrostatically interact with transferring ions. The sensitivity of an interface modified with mesoporous material will vary depending on the thickness of the membrane and must be optimised. Slevin et al. first modified the liquid liquid interface with phospholipid monolayer that subsequently served as the cushion for polyelectrolyte multilayer build out of cationic poly(allymamine) and anionic poly(styrenesulfonate) [31]. They observed characterising zig-zag patterns for the transfer rate as a function of polyelectrolyte multilayer thickness for cationic $\mathrm{TEA}^{+}$and tacrine. For thicker multilayer, the transfer of $\mathrm{TEA}^{+}$was only slightly affected when poly(styrenesulfonate) was used as the terminal layer and almost excluded when poly(allylamine) was further added. Polypyrrole [158,159] and polystyrene [160] films were also found to have good sealing properties as revealed with ion transfer voltammetry e.g. polymeric film formed out of 4(pyrrol-1-yl)phenyloxyacetic acid blocked the transfer of $T M A^{+}$and $P F_{6}^{-}$whereas the addition of cyclodextrin (tert-butyl- $\gamma$-cyclodextrin) allowed the formation of a pore permeable for small inorganic ions. Very recently $\mathrm{Hu}$ et al. [213] used commercial anion exchange membrane with the quaternary ammonium cations as the fixed charged groups to support the ITIES. They made 
number of interesting observation: (i) presence of anion exchange membrane at the ITIES allowed the extension of the potential window to almost $1.8 \mathrm{~V}$; (ii) the transfer of $\mathrm{SO}_{4}^{2-}, \mathrm{NO}_{2}^{-}$, $\mathrm{ClO}_{4}^{-}, \mathrm{NO}_{3}^{-}$and acetate could be followed with ion transfer voltammetry and (iii) set of well separated adsorptive stripping differential pulse voltammetry peaks were recorded for the mixture of $\mathrm{Cl}^{-}, \mathrm{SO}_{4}^{2-}, \mathrm{NO}_{2}^{-}, \mathrm{ClO}_{4}^{-}$when gelled organic phase was employed.

\section{Conclusions and outlook}

We believe that the effort related to the modification of electrified liquid - liquid interfaces will be keep on growing. More effort is required to transform inherent and unique properties of the ITIES into real applications of societal importance. In this respect, we would like to address some improvements and challenges to specific domains where electrified liquid junctions found their place (Table 2). In the view of the widespread use of electrochemistry at the ITIES, the toxicity of the organic phase remains a major issue. Recent years have seen the increasing use of solvent of lower toxicity (e.g. trifluorotoluene), than 1,2-dichloroethane and nitrobenzene. Development of very hydrophobic ionic liquids would further improve the chances of seeing applications of liquid-liquid electrochemistry [214-216]. Leaving out few exceptions, one of the biggest limitation of electrochemical analysis, including ITIES based sensors is selectivity. For solid state electrodes, this limitation is frequently solved by a surface modification. By analogy, we do believe that the effort related to the improvement of the electroanalytical performance of the analysis at ITIES lays in a smart interfacial modification. This can be achieved via: (i) development of new membranes allowing selective ion transfer including size or charge exclusion; (ii) introduction of interfacially fixed analyte selective groups and (iii) improvement of current miniaturization techniques allowing preparation of cheaper and readily available micro- and nanoITIES in a form of patterned membranes or capillaries. Interfacial catalysis at the liquid - liquid interface was so far mainly focused on HER and ORR that are without doubt of highest technological importance. In addition to this two reaction, we anticipate that both immiscible liquids can accommodate other redox couples. Beside solid catalytic NPs that were used so far to decorate interfacial region, we await for molecular catalysts that can hold surface active properties or enzymes that can all be accommodated within the interfacial region. For the latter, solutions allowing their immobilization with simultaneous prevention of denaturation need to be developed. Discontinuous properties of the ITIES allows easy and straightforward assembly of amphiphilic chromophores that together can find application as a soft solar cell. In this context, the link needs to be made between synthetic chemistry and electrochemistry at the liquid - liquid interface in order to design and implement 
new molecules that upon photon absorption are able to induce photovoltage across the polarizable liquid junction. The main challenge related to the ITIES based solar cells is the increase of turnover efficiency. Of interest is an increase of the available interfacial surface area that can be achieved via 3D approach. In addition to electricity production, photon absorbed via chromophores deposited at the ITIES can serve to drive artificial photosynthesis.

Table 2. Summary of nanomaterials immobilized at the ITIES

\begin{tabular}{|c|c|c|}
\hline Type of nanomaterials & Added value & Challenges \\
\hline Phospholipid monolayers & - Biomimetism & 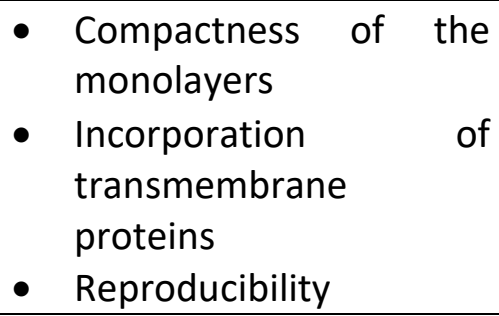 \\
\hline Porphyrin assembly & - $\quad$ Photo-induced ET & - Turnover efficiency \\
\hline $\begin{array}{l}\text { Metal NPs(assembled or } \\
\text { electrogenerated) }\end{array}$ & $\begin{array}{l}\text { - Assembly controlled by } \\
\text { potential } \\
\text { - Redox catalysis } \\
\text { Optical reflectivity }\end{array}$ & $\begin{array}{l}\text { - Understanding of the } \\
\text { electrogeneration } \\
\text { mechanism }\end{array}$ \\
\hline Inorganic porous materials & $\begin{array}{l}\text { - } \quad \text { Controlled porosity; } \\
\text { - Surface chemistry; }\end{array}$ & - Selectivity \\
\hline Polymeric films & - Rich chemistry & $\begin{array}{l}\text { - Understanding of the } \\
\text { formation mechanism }\end{array}$ \\
\hline Carbon based materials & $\begin{array}{l}\text { - High specific surface } \\
\text { area; } \\
\text { - Electron shuttle } \\
\text { - Surface chemistry }\end{array}$ & $\begin{array}{l}\text { - Formation of a stable } \\
\text { dispersion that can } \\
\text { assemble at the } \\
\text { interface. }\end{array}$ \\
\hline Fabricated nano-interfaces & $\begin{array}{l}\text { - Increased mass transfer; } \\
\text { - Interfacial stabilization }\end{array}$ & - Fabrication complexity \\
\hline
\end{tabular}

\section{Acknowledgments}

AGQ, GH and AW are grateful to the the Agence Nationale pour la Recherche (Grant No. ANR-14-CE14-0002-01) for the financial support of this work.

\section{References}

[1] J.B. Edel, A.A. Kornyshev, M. Urbakh, Self-Assembly of Nanoparticle Arrays for Use as Mirrors, Sensors, and Antennas, ACS Nano. 7 (2013) 9526-9532. 
doi:10.1021/nn405712r.

[2] S.G. Booth, R.A.W. Dryfe, Assembly of Nanoscale Objects at the Liquid/Liquid Interface, J. Phys. Chem. C. 119 (2015) 23295-23309. doi:10.1021/acs.jpcc.5b07733.

[3] K. Piradashvili, E.M. Alexandrino, F.R. Wurm, K. Landfester, Reactions and Polymerizations at the Liquid-Liquid Interface, Chem. Rev. 116 (2016) 2141-2169. doi:10.1021/acs.chemrev.5b00567.

[4] N. Glaser, D.J. Adams, A. Böker, G. Krausch, Janus Particles at Liquid-Liquid Interfaces, Langmuir. 22 (2006) 5227-5229. doi:10.1021/la060693i.

[5] C. Gavach, T. Mlodnicka, J. Guastalla, Sur la possibilité de phénomènes de surtension à l'interface liquide-liquide entre solutions organiques et solutions aqueuses, C. R. Acad. Sc. Paris. 266 (1968) 1196-1199.

[6] J. Guastalla, Irréversibilités dans les propriétés électriques de l'interface entre des solutions ioniques non miscibles, C. R. Acad. Sc. Paris. 269 (1969) 1360-1363.

[7] J. Guastalla, Interface hysteresis and negative differential conductance at liquid-liquid junction between non-miscible ionic solutions, Nature. 227 (1970) 485-486.

[8] Z. Samec, V. Mareček, J. Weber, Charge transfer between two immiscible electrolyte solutions, J. Electroanal. Chem. 100 (1979) 841-852.

[9] Z. Samec, Electrochemistry at the interface between two immiscible electrolyte solutions, Pure Appl. Chem. 76 (2004) 2147-2180.

[10] H.A. Santos, V. García-Morales, C.M. Pereira, Electrochemical properties of phospholipid monolayers at liquid-liquid interfaces., ChemPhysChem. 11 (2010) 2841. doi:10.1002/cphc.200900609.

[11] H. Jänchenová, K. Štulík, V. Mareček, Adsorption and ion-pairing interactions of phospholipids in the system of two immiscible electrolyte solutions. Part II: The formation and behaviour of a lecithin layer at the water/1,2-dichloroethane interface in the presence of multivalent anions in the, J. Electroanal. Chem. 604 (2007) 109114. doi:10.1016/j.jelechem.2007.03.011.

[12] H. Jänchenová, A. Lhotský, K. Štulík, V. Mareček, Adsorption and ion-pairing interactions of phospholipids in the system of two immiscible electrolyte solutions Part I. The behaviour of lecithin at the water/1,2-dichloroethane interface, compared with that of trimethyloctadecylammonium cation, J. Electroanal. Chem. 601 (2007) 101-106. doi:10.1016/j.jelechem.2006.10.025.

[13] H. Jänchenová, K. Štulík, V. Mareček, Adsorption and ion-pairing interactions of phospholipids in the system of two immiscible electrolyte solutions, J. Electroanal. Chem. 612 (2008) 186-190. doi:10.1016/j.jelechem.2007.09.024.

[14] T. Kakiuchi, M. Kotani, J. Noguchi, M. Nakanishi, M. Senda, Phase transition and ion permeability of phosphatidylcholine monolayers at the polarized oil/water interface, J. Colloid Interface Sci. 149 (1992) 279-289. doi:10.1016/0021-9797(92)90415-I.

[15] T. Kakiuchi, T. Kondo, M. Senda, Divalent Cation-Induced Phase Transition of Phosphatidylserine Monolayer at the Polarized Oil-Water Interface and Its Influance on the Ion-Transfer Processes, Bull. Chem. Soc. Jpn. 63 (1990) 3270-3276.

[16] T. Kakiuchi, T. Kondo, M. Kotani, M. Senda, Ion Permeability of 
Dilauroylphosphatidylethanolamine Monolayer at the Polarized Nitrobenzene/Water Interface, Langmuir. 8 (1992) 169-175. doi:10.1021/la00037a032.

[17] T. Kakiuchi, Y. Masataka, T. Osakai, M. Senda, Monolayer formation of dilauroylphosphatidylcholine at the polarized nitrobenzene-water interface, Bull. Korean Chem. Soc. 60 (1987) 4223-4228.

[18] T. Kakiuchi, M. Nakanishi, M. Senda, The Electrocapillary Curves of the Phosphatidylcholine Monolayer at the Polarized Oil-Water Interface. I. Measurement of Interfacial Tension Using Computer-Aided Pendant-Drop Method, Bull. Chem. Soc. Jpn. 61 (1988) 1845-1851.

[19] T. Kakiuchi, M. Nakanishi, M. Senda, The electrocapillary curves of the phosphatidylcholine monolayer at the polarized oil-water interface. II. Double layer structure of dilauroylphosphatidylcholine monolayer at the nitrobenzene-water interface., Bull. Chem. Soc. Jpn. 62 (1989) 403-409. doi:10.1246/bcsj.61.1845.

[20] A.-K. Kontturi, K. Kontturi, L. Murtoms, B. Quinn, V.J. Cunnane, Study of ion transfer across phospholipid monolayers adsorbed at micropipette ITIES, J. Electroanal. Chem. 424 (1997) 69-74.

[21] D. Grandell, L. Murtomäki, Surface Pressure Control of Phospholipid Monolayers at the Water/1,2-Dichloroethane Interface, Langmuir. 14 (1998) 556-559.

[22] D. Grandell, L. Murtomaki, K. Kontturi, G. Sundholm, Phospholipid monolayers studied by a combination of cyclic voltammetry and Langmuir techniques at the water 1,2dichloroethane interface, J. Electroanal. Chem. 463 (1999) 242-247.

[23] A. Malkia, P. Liljeroth, A.-K. Kontturi, K. Kontturi, Electrochemistry at Lipid MonolayerModified Liquid-Liquid Interfaces as an Improvement to Drug Partitioning Studies, J. Phys. Chem. B. 105 (2001) 10884-10892.

[24] H.A. Santos, S. Carlsson, L. Murtomäki, K. Kontturi, Effect of gramicidin on phospholipid-modified monolayers and on ion transfer at a liquid-liquid interface., Chemphyschem. 8 (2007) 913-920. doi:10.1002/cphc.200600767.

[25] A. Malkia, P. Liljeroth, K. Kontturi, Membrane activity of ionisable drugs - a task for liquid-liquid electrochemistry?, Electrochem. Commun. 5 (2003) 473-479. doi:10.1016/S1388-2481(03)00107-3.

[26] L. Murtomaki, J.A. Manzanares, S. Mafé, K. Kontturi, Phospholipids at Liquid-Liquid Interfaces and Their Effect on Charge Transfer, in: A.G. Volkov (Ed.), Liq. Interfaces Chem. Biol. Pharm. Appl., Marcel Dekker, New York, 2001. doi:10.1201/9780203908754.ch22.

[27] R. Pichot, R.L. Watson, I.T. Norton, Phospholipids at the interface: current trends and challenges, Int. J. Mol. Sci. 14 (2013) 11767-11794. doi:10.3390/ijms140611767.

[28] G. Herzog, V. Kam, D.W.M. Arrigan, Electrochemical behaviour of haemoglobin at the liquid/liquid interface, Electrochim. Acta. 53 (2008) 7204-7209.

doi:10.1016/j.electacta.2008.04.072.

[29] B.R. Silver, V. Fülöp, P.R. Unwin, Protein crystallization at oil/water interfaces, New J. Chem. 35 (2011) 602. doi:10.1039/c0nj00822b.

[30] S. Ulmeanu, Voltammetric characterisation of polyelectrolyte adsorption/transfer at the water 1,2-DCE interface, Electrochem. Commun. 3 (2001) 539-543. 
doi:10.1016/S1388-2481(01)00209-0.

[31] C.J. Slevin, A. Malkia, P. Liljeroth, M. Toiminen, Kyosti Kontturi, Electrochemical Characterization of Polyelectrolyte Multilayers Deposited at Liquid - Liquid Interfaces, Langmuir. 19 (2003) 1287-1294.

[32] H. Katano, I. Kameoka, Y. Murayama, H. Tatsumi, T. Tsukatani, M. Makino, Voltammetric study of the transfer of polyammonium ions at nitrobenzene / water interface., Anal. Sci. 20 (2004) 1581-1585. doi:10.2116/analsci.20.1581.

[33] S. Hakkarainen, S.L. Gilbert, A.-K. Kontturi, K. Kontturi, Amperometric method for determining the degree of complexation of polyelectrolytes with cationic surfactants., J. Colloid Interface Sci. 272 (2004) 404-10. doi:10.1016/j.jcis.2004.01.033.

[34] L. Zhang, Y. Kitazumi, T. Kakiuchi, Potential-dependent adsorption and transfer of poly(diallyldialkylammonium) ions at the nitrobenzene |water interface., Langmuir. 27 (2011) 13037-13042. doi:10.1021/la2028077.

[35] J.S. Riva, D.M. Beltramo, L.M. Yudi, Adsorption-desorption mechanism of a cationic polyelectrolyte based on dimethylaminoethyl polymethacrylates at the water/1,2dichloroethane interface, Electrochim. Acta. 115 (2014) 370-377. doi:10.1016/j.electacta.2013.10.156.

[36] C.I. Cámara, M.V.C. Quiroga, N. Wilke, A. Jimenez-Kairuz, L.M. Yudi, Effect of chitosan on distearoylphosphatidylglycerol films at air/water and liquid/liquid interfaces, Electrochim. Acta. 94 (2013) 124-133. doi:10.1016/j.electacta.2013.01.137.

[37] J.S.S. Riva, R. Iglesias, L.M. Yudi, Electrochemical adsorption of a cationic cellulosic polymer by ion pair formation at the interface between two immiscible electrolyte solutions, Electrochim. Acta. 107 (2013) 584-591. doi:10.1016/j.electacta.2013.06.008.

[38] J.S. Riva, L.M. Yudi, The effect of the functionalization and molecular weight of cationic dextran polyelectrolytes on their electrochemical behavior at the water/1,2dichloroethane interface., Phys. Chem. Chem. Phys. 17 (2015) 1644-52. doi:10.1039/c4cp03483j.

[39] J.S. Riva, C.I. Cámara, A. V. Juarez, L.M. Yudi, Electrochemical behaviour of cationic polyelectrolytes at a polarized liquid/liquid interface, J Appl Electrochem. 44 (2014) 1381-1392. doi:10.1007/s10800-014-0747-2.

[40] H. Nagatani, T. Ueno, T. Sagara, Spectroelectrochemical analysis of ion-transfer and adsorption of the PAMAM dendrimer at a polarized liquid/liquid interface, Electrochim. Acta. 53 (2008) 6428-6433. doi:10.1016/j.electacta.2008.04.081.

[41] H. Sakae, H. Nagatani, K. Morita, H. Imura, Spectroelectrochemical characterization of dendrimer-porphyrin associates at polarized liquid|liquid interfaces., Langmuir. 30 (2014) 937-45. doi:10.1021/la404079m.

[42] L. Poltorak, K. Morakchi, G. Herzog, A. Walcarius, Electrochemical characterization of liquid-liquid micro-interfaces modified with mesoporous silica, Electrochim. Acta. 179 (2015) 9-15. doi:10.1016/j.electacta.2015.01.129.

[43] M.A. González-Fuentes, J. Manríquez, R. Antaño-López, L. a. Godínez, Electrochemically driven transfer of carboxyl-terminated PAMAM dendrimers at the water/dichloroethane interface, Electrochem. Commun. 12 (2010) 137-139. 
doi:10.1016/j.elecom.2009.11.007.

[44] A. Berduque, M.D. Scanlon, C.J. Collins, D.W.M.M. Arrigan, Electrochemistry of NonRedox-Active Poly(propylenimine) and Poly(amidoamine) Dendrimers at Liquid-Liquid Interfaces, Langmuir. 23 (2007) 7356-7364. doi:10.1021/la063294w.

[45] G. Herzog, S. Flynn, C. Johnson, D.W.M. Arrigan, Electroanalytical behavior of poly-Ilysine dendrigrafts at the interface between two immiscible electrolyte solutions, Anal. Chem. 84 (2012) 5693-5699. doi:10.1021/ac300856w.

[46] M. Calderon, L.M.A. Monzón, M. Martinelli, A. V Juarez, M.C. Strumia, L.M. Yudi, Electrochemical study of a dendritic family at the water/1,2-dichloroethane interface., Langmuir. 24 (2008) 6343-50. doi:10.1021/la704052b.

[47] H. Nagatani, T. Sakamoto, T. Torikai, T. Sagara, Encapsulation of Anilinonaphthalenesulfonates in Carboxylate-Terminated PAMAM Dendrimer at the Polarized Water|1,2-Dichloroethane Interface, Langmuir. 26 (2010) 17686-17694. doi:10.1021/la1032477.

[48] Z. Samec, A. Trojanek, J. Langmaier, E. Samcova, Cyclic voltammetry of biopolymer heparin at PVC plasticized liquid membrane, Electrochem. Commun. 5 (2003) 867870. doi:10.1016/j.elecom.2003.08.009.

[49] S. Amemiya, X. Yang, T.L. Wazenegger, Voltammetry of the Phase Transfer of Polypeptide Protamines across Polarized Liquid / Liquid Interfaces Voltammetry of the Phase Transfer of Polypeptide Protamines across Polarized Liquid / Liquid Interfaces, J. Am. Chem. Soc. 125 (2003) 11832-11833. doi:10.1021/ja036572b.

[50] D.W.M. Arrigan, Voltammetry of proteins at liquid-liquid interfaces, Annu. Rep. Prog. Chem., Sect C Phys. Chem. 109 (2013) 167-188. doi:10.1039/c3pc90007j.

[51] E. Alvarez De Eulate, L. Serls, D.W.M. Arrigan, Detection of haemoglobin using an adsorption approach at a liquid-liquid microinterface array, Anal. Bioanal. Chem. 405 (2013) 3801-3806. doi:10.1007/s00216-012-6622-2.

[52] S. Amemiya, Y. Kim, R. Ishimatsu, B. Kabagambe, Electrochemical heparin sensing at liquid/liquid interfaces and polymeric membranes, Anal. Bioanal. Chem. 399 (2011) 571-579. doi:10.1007/s00216-010-4056-2.

[53] M.D. Scanlon, J. Strutwolf, D.W.M. Arrigan, Voltammetric behaviour of biological macromolecules at arrays of aqueous|organogel micro-interfaces, Phys. Chem. Chem. Phys. 12 (2010) 10040-10047. doi:10.1039/c003323e.

[54] M.I. Gugeshashvili, V.I. Portnov, A.G. Volkov, L.N. Chekulaeva, V.S. Markin, Emulsion photobioelectrochemistry: bacteriorhodopsin phototransfer of protons through the water/lipid interface, J. Electroanal. Chem. 321 (1991) 139-158. doi:10.1016/00220728(91)85591-C.

[55] A.G. Volkov, D.W. Deamer, Energy Conversion At Liquid / Liquid Interfaces : Artificial Photosynthetic Systems, Electrochim. Acta. 40 (1995) 2849-2868.

[56] L.A. Drachev, A.D. Kaulen, V.P. Skulachev, V.M. Voytsitsky, Bacteriorhodopsinmediated photoelectric responses in lipid/water systems, J. Membr. Biol. 65 (1982) 112. doi:10.1007/BF01870463.

[57] E. Alvarez de Eulate, S. O'Sullivan, D.W.M. Arrigan, Electrochemically Induced Formation of Cytochrome c Oligomers at Soft Interfaces, ChemElectroChem. 4 (2017) 
898-904. doi:10.1002/celc.201600851.

[58] T. Kakiuchi, Electrochemical instability of the liquid|liquid interface in the presence of ionic surfactant adsorption, J. Electroanal. Chem. 536 (2002) 63-69. doi:10.1016/S0022-0728(02)01204-4.

[59] T. Kakiuchi, Potential-dependent adsorption and partitioning of ionic components at a liquid|liquid interface, J. Electroanal. Chem. 496 (2001) 137-142. doi:10.1016/S00220728(00)00310-7.

[60] Y. Kitazumi, T. Kakiuchi, A model of the electrochemical instability at the liquid|liquid interface based on the potential-dependent adsorption and Gouy's double layer theory, J. Electroanal. Chem. 648 (2010) 8-14. doi:10.1016/j.jelechem.2010.07.007.

[61] Y. Kitazumi, T. Kakiuchi, Potential-dependent adsorption of decylsulfate and decylammonium prior to the onset of electrochemical instability at the 1,2dichloroethane / water interface., Langmuir. 25 (2009) 8062-8068. doi:10.1021/la9005696.

[62] T. Kakiuchi, M. Chiba, N. Sezaki, M. Nakagawa, Cyclic voltammetry of the transfer of anionic surfactant across the liquid - liquid interface manifests electrochemical instability, Electrochem. Commun. 4 (2002) 701-704.

[63] T. Kakiuchi, N. Nishi, T. Kasahara, M. Chiba, Regular irregularity in the transfer of anionic surfactant across the liquid/liquid interface., Chemphyschem. 4 (2003) 17985. doi:10.1002/cphc.200390028.

[64] M. Chowdhury, R. Kataky, Emulsification at the Liquid/Liquid Interface: Effects of Potential, Electrolytes and Surfactants, ChemPhysChem. 17 (2016) 105-111. doi:10.1002/cphc.201500847.

[65] T. Kasahara, N. Nishi, M. Yamamoto, T. Kakiuchi, Electrochemical instability in the transfer of cationic surfactant across the 1,2-dichloroethane/water interface., Langmuir. 20 (2004) 875-81. http://www.ncbi.nlm.nih.gov/pubmed/15773118.

[66] T. Kakiuchi, Electrochemical instability in facilitated transfer of alkaline-earth metal ions across the nitrobenzene / water interface, J. Electroanal. Chem. 569 (2004) 287291. doi:10.1016/j.jelechem.2004.02.029.

[67] A.R. Brown, L.J. Yellowlees, H.H. Girault, Photoinitiated electron-transfer reactions across the interface between two immiscible electrolyte solutions, J. Chem. Soc. Faraday Trans. 89 (1993) 207. doi:10.1039/ft9938900207.

[68] D.J. Fermín, H. Dung Duong, Z. Ding, O. Brevet, H.H. Girault, H.D. Duong, et al., Photoinduced electron transfer at liquid/liquid interfaces Part II. A study of the electron transfer and recombination dynamics by intensity modulated photocurrent spectroscopy (IMPS), Phys. Chem. Chem. Phys. 1 (1999) 1461-1467. doi:10.1039/a900142e.

[69] H. Jensen, J.J. Kakkassery, H. Nagatani, D.J. Fermin, H.H. Girault, Photoinduced electron transfer at liquid vertical bar liquid interfaces. Part IV. Orientation and reactivity of zinc tetra(4-carboxyphenyl) porphyrin self-assembled at the water vertical bar 1,2-dichloroethane junction, J. Am. Chem. Soc. 122 (2000) 10943-10948.

[70] D.J. Fermin, Z.F. Ding, H.D. Duong, P.F. Brevet, H.H. Girault, Photoinduced electron transfer at liquid/liquid interfaces. I. Photocurrent measurements associated with 
heterogeneous quenching of zinc porphyrins, J. Phys. Chem. B. 102 (1998) 1033410341. doi:10.1021/jp983196m.

[71] D. Fermin, H. Duong, Z. Ding, P. Brevet, H. Girault, Solar energy conversion using dyesensitised liquid|liquid interfaces, Electrochem. Commun. 1 (1999) 29-32. doi:http://dx.doi.org/10.1016/S1388-2481(98)00009-5.

[72] D.J. Fermín, H.D. Duong, Z. Ding, P.F. Brevet, H.H. Girault, Photoinduced electron transfer at liquid/liquid interfaces. Part III. Photoelectrochemical responses involving porphyrin ion pairs, J. Am. Chem. Soc. 121 (1999) 10203-10210. doi:10.1021/ja992215i.

[73] H. Nagatani, R.A. Iglesias, D.J. Fermin, P.-F. Brevet, H.H. Girault, Adsorption Behavior of Charged Zinc Porphyrins at the Water / 1, 2-Dichloroethane Interface Studied by Potential Modulated Fluorescence Spectroscopy, J. Phys. Chem. B. 104 (2000) 68696876.

[74] H. Nagatani, A. Piron, P.F. Brevet, D.J. Fermín, H.H. Girault, Surface second harmonic generation of cationic water-soluble porphyrins at the polarized water|1,2dichloroethane interface, Langmuir. 18 (2002) 6647-6652. doi:10.1021/la0256329.

[75] H. Nagatani, Z. Samec, P. Brevet, D.J. Fermin, H.H. Girault, Adsorption and aggregation of meso-tetrakis (4-carboxyphenyl) porphyrinato Zinc (II) at the polarized water| 1, 2dichloroethane interface, J. Phys. Chem. 107 (2003) 786-790. doi:10.1021/jp026819b.

[76] B. Su, N. Eugster, H.H. Girault, Reactivity of Monolayer-Protected Gold Nanoclusters at Dye-Sensitized Liquid/Liquid Interfaces, J. Am. Chem. Soc. 127 (2005) 10760-10766. doi:10.1021/ja052415w.

[77] H. Nagatani, H. Sakae, T. Torikai, T. Sagara, H. Imura, Photoinduced Electron Transfer of PAMAM Dendrimer-Zinc(II) Porphyrin Associates at Polarized Liquid|Liquid Interfaces, Langmuir. (2015) 150528143435008. doi:10.1021/acs.langmuir.5b01165.

[78] B. Su, I. Hatay, A. Trojánek, Z. Samec, T. Khoury, C.P. Gros, et al., Molecular electrocatalysis for oxygen reduction by cobalt porphyrins adsorbed at liquid/liquid interfaces, J. Am. Chem. Soc. 132 (2010) 2655-2662. doi:10.1021/ja908488s.

[79] A.J. Olaya, D. Schaming, P.F. Brevet, H. Nagatani, H.J. Xu, M. Meyer, et al., Interfacial self-assembly of water-soluble cationic porphyrins for the reduction of oxygen to water, Angew. Chem. Int. Ed. 51 (2012) 6447-6451. doi:10.1002/anie.201202266.

[80] A.J. Olaya, D. Schaming, P.F. Brevet, H. Nagatani, T. Zimmermann, J. Vanicek, et al., Self-assembled molecular rafts at liquid| liquid interfaces for four-electron oxygen reduction, J. Am. Chem. Soc. 134 (2012) 498-506. doi:10.1021/ja2087322.

[81] P. Peljo, L. Murtomäki, T. Kallio, H.J. Xu, M. Meyer, C.P. Gros, et al., Biomimetic oxygen reduction by cofacial porphyrins at a liquid-liquid Interface, J. Am. Chem. Soc. 134 (2012) 5974-5984. doi:10.1021/ja3004914.

[82] A. Trojánek, J. Langmaier, S. Záliš, Z. Samec, Mechanistic model of the oxygen reduction catalyzed by a metal-free porphyrin in one- and two-phase liquid systems, Electrochim. Acta. 110 (2013) 816-821. doi:10.1016/j.electacta.2012.12.100.

[83] A. Trojanek, H. Kvapilova, J. Langmaier, H. Kvapilova, S. Za, Inhibitory Effect of Water on the Oxygen Reduction Catalyzed by Cobalt ( II ) Tetraphenylporphyrin, J. Phys. Chem. A. 118 (2014) 2018-2028. 
[84] H. Duan, D. Wang, D.G. Kurth, H. Möhwald, Directing self-assembly of nanoparticles at water/oil interfaces, Angew. Chem. Int. Ed. 43 (2004) 5639-5642. doi:10.1002/anie.200460920.

[85] W.H. Binder, Supramolecular assembly of nanoparticles at liquid-liquid interfaces., Angew. Chem. Int. Ed. 44 (2005) 5172-5175. doi:10.1002/anie.200501220.

[86] A. Böker, J. He, T. Emrick, T.P. Russell, Self-assembly of nanoparticles at interfaces, Soft Matter. 3 (2007) 1231-1248. doi:10.1039/b706609k.

[87] M. Grzelczak, J. Vermant, E.M. Furst, L.M. Liz-Marzan, Directed self-assembly of nanoparticles, ACS Nano. 4 (2010) 3591-3605. doi:10.1021/nn100869j.

[88] L. Hu, M. Chen, X. Fang, L. Wu, Oil-water interfacial self-assembly: a novel strategy for nanofilm and nanodevice fabrication, Chem. Soc. Rev. 41 (2012) 1350-1362. doi:10.1039/C1CS15189D.

[89] B. Su, J.P. Abid, D.J. Fermin, H.H. Girault, H. Hoffmannova, P. Krtil, et al., Reversible voltage-induced assembly of Au nanoparticles at liquid vertical bar liquid interfaces, J. Am. Chem. Soc. 126 (2004) 915-919.

[90] M.E. Flatté, A.A. Kornyshev, M. Urbakh, Understanding voltage-induced localization of nanoparticles at a liquid-liquid interface, J. Phys. Condens. Matter. 20 (2008) 73102. doi:10.1088/0953-8984/20/7/073102.

[91] E. Smirnov, M.D. Scanlon, D. Momotenko, H. Vrubel, M.A. Méndez, P.-F. Brevet, et al., Gold Metal Liquid-Like Droplets, ACS Nano. 8 (2014) 9471-9481. doi:10.1021/nn503644v.

[92] E. Smirnov, P. Peljo, M.D. Scanlon, H.H. Girault, Interfacial Redox Catalysis on Gold Nanofilms at Soft Interfaces, ACS Nano. 9 (2015) 6565-6575. doi:10.1021/acsnano.5b02547.

[93] H. Jensen, D.J. Fermín, J.E. Moser, H.H. Girault, Organization and Reactivity of Nanoparticles at Molecular Interfaces. Part I. Photoelectrochemical Responses Involving TiO 2 Nanoparticles Assembled at Polarizable Water|1,2-Dichloroethane Junctions, J. Phys. Chem. B. 106 (2002) 10908-10914. doi:10.1021/jp0261253.

[94] D.J. Fermin, H. Jensen, J.E. Moser, H.H. Girault, Organisation and reactivity of nanoparticles at molecular interfaces. Part II.+ Dye sensitisation of TiO2 nanoparticles assembled at the water | 1,2-dichloroethane interface, ChemPhysChem. 4 (2003) 8589. doi:10.1002/cphc.200390013.

[95] D. Schaming, M. Hojeij, N. Younan, H. Nagatani, H.J. Lee, H.H. Girault, Photocurrents at polarized liquid |liquid interfaces enhanced by a gold nanoparticle film, Phys. Chem. Chem. Phys. 13 (2011) 17704-17711. doi:10.1039/c1cp22072a.

[96] E. Smirnov, P. Peljo, M.D. Scanlon, F. Gumy, H.H. Girault, Self-healing gold mirrors and filters at liquid-liquid interfaces, Nanoscale. 8 (2016) 7723-7737. doi:10.1039/C6NR00371K.

[97] E. Smirnov, P. Peljo, M.D. Scanlon, H.H. Girault, Gold Nanofilm Redox Catalysis for Oxygen Reduction at Soft Interfaces, Electrochim. Acta. 197 (2016) 362-373. doi:10.1016/j.electacta.2015.10.104.

[98] B. Su, D.J. Fermín, J.P. Abid, N. Eugster, H.H. Girault, Adsorption and photoreactivity of CdSe nanoparticles at liquid/liquid interfaces, J. Electroanal. Chem. 583 (2005) 241- 
247. doi:10.1016/j.jelechem.2005.01.043.

[99] S. Biswas, L.T. Drzal, A novel approach to create a highly ordered monolayer film of graphene nanosheets at the liquid-liquid interface, Nano Lett. 9 (2009) 167-172. doi:10.1021/nl802724f.

[100] M.M. Gudarzi, F. Sharif, Self assembly of graphene oxide at the liquid-liquid interface: A new route to the fabrication of graphene based composites, Soft Matter. 7 (2011) 3432-3440. doi:10.1039/c0sm01311k.

[101] X. Bian, M.D. Scanlon, S. Wang, L. Liao, Y. Tang, B. Liu, et al., Floating conductive catalytic nano-rafts at soft interfaces for hydrogen evolution, Chem. Sci. 4 (2013) 3432. doi:10.1039/c3sc51290h.

[102] P. Asuri, S.S. Karajanagi, J.S. Dordick, R.S. Kane, Directed Assembly of Carbon Nanotubes at Liquid - Liquid Interfaces : Nanoscale Conveyors for Interfacial Biocatalysis, J. Am. Chem. Soc. 128 (2006) 1046-1047.

[103] P. Ge, M.D. Scanlon, P. Peljo, X. Bian, H. Vubrel, A. O’Neill, et al., Hydrogen evolution across nano-Schottky junctions at carbon supported MoS2 catalysts in biphasic liquid systems, Chem. Commun. 48 (2012) 6484. doi:10.1039/c2cc31398g.

[104] W. Hirunpinyopas, A.N.J. Rodgers, S.D. Worrall, M.A. Bissett, R.A.W. Dryfe, Hydrogen Evolution at Liquid|Liquid Interfaces Catalyzed by 2D Materials, ChemNanoMat. 3 (2017) 428-435. doi:10.1002/cnma.201700047.

[105] P.S. Toth, Q.M. Ramasse, M. Velický, R.A.W. Dryfe, Functionalization of graphene at the organic/water interface, Chem. Sci. 6 (2015) 1316-1323. doi:10.1039/C4SC03504F.

[106] P.S. Toth, A.N.J. Rodgers, A.K. Rabiu, R.A.W. Dryfe, Electrochemical activity and metal deposition using few-layer graphene and carbon nanotubes assembled at the liquidliquid interface, Electrochem. Commun. 50 (2015) 6-10.

doi:10.1016/j.elecom.2014.10.010.

[107] A. Trojánek, V. Mareček, Z. Samec, Visualization of the interfacial turbulence associated with remarkable faradaic current amplification at a polarized water/1,2dichloroethane interface, Electrochem. Commun. 80 (2017) 1-4. doi:10.1016/j.elecom.2017.04.019.

[108] M. Etienne, J. Cortot, A. Walcarius, Preconcentration Electroanalysis at SurfactantTemplated Thiol-Functionalized Silica Thin Films, Electroanalysis. 19 (2007) 129-138. doi:10.1002/elan.200603677.

[109] A. Walcarius, E. Sibottier, M. Etienne, J. Ghanbaja, Electrochemically assisted selfassembly of mesoporous silica thin films., Nat. Mater. 6 (2007) 602-608. doi:10.1038/nmat1951.

[110] X. Zhang, W. Wu, J. Wang, C. Liu, Evaporation-Induced Self-Assembly of AminoFunctionalized Mesoporous Silica Thin Films by Sol-Gel Process, J. Am. Ceram. Soc. 90 (2007) 965-968. doi:10.1111/j.1551-2916.2006.01477.x.

[111] V. Mareček, H. Jänchenová, Electrochemically controlled formation of a silicate membrane at a liquid/liquid interface, J. Electroanal. Chem. 558 (2003) 119-123. doi:10.1016/S0022-0728(03)00386-3.

[112] L. Poltorak, G. Herzog, A. Walcarius, In-situ formation of mesoporous silica films 
controlled by ion transfer voltammetry at the polarized liquid-liquid interface, Electrochem. Commun. 37 (2013) 76-79. doi:10.1016/j.elecom.2013.10.018.

[113] L. Poltorak, G. Herzog, A. Walcarius, Electrochemically assisted generation of silica deposits using a surfactant template at liquid/liquid micro-interfaces, Langmuir. 30 (2014) 11453-11463. doi:10.1021/la501938g.

[114] L. Poltorak, M. Dossot, G. Herzog, A. Walcarius, Interfacial processes studied by coupling electrochemistry at the polarised liquid-liquid interface with in situ confocal Raman spectroscopy., Phys. Chem. Chem. Phys. 16 (2014) 26955-26962. doi:10.1039/c4cp03254c.

[115] Y. Liu, A. Holzinger, P. Knittel, L. Poltorak, A. Gamero-Quijano, W.D.A. Rickard, et al., Visualization of Diffusion within Nanoarrays, Anal. Biochem. 88 (2016) 6689-6695. doi:10.1021/acs.analchem.6b00513.

[116] S. Dai, M.C. Burleigh, Y.H. Ju, H.J. Gao, J.S. Lin, S.J. Pennycook, et al., Hierarchically Imprinted Sorbents for the Separation of Metal Ions, J. Am. Chem. Soc. 122 (2000) 992-993. doi:10.1021/ja993168x.

[117] V. Zelenak, D. Halamova, L. Gaberova, E. Bloch, P. Llewellyn, Amine-modified SBA-12 mesoporous silica for carbon dioxide capture: Effect of amine basicity on sorption properties, Microporous Mesoporous Mater. 116 (2008) 358-364. doi:10.1016/j.micromeso.2008.04.023.

[118] D. Zhao, P. Yang, B.F. Chmelka, G.D. Stucky, Multiphase Assembly of MesoporousMacroporous Membranes The synthesis of inorganic-organic composites and mesoporous materials with structures and functions over different length scales has ramifications in diverse areas, such as large-molecule catalysis, Chem. Mater. 11 (1999) 1174-1178.

[119] J. Niedziolka, M. Opallo, Electrochemically assisted sol-gel process at a three phase junction, Electrochem. Commun. 10 (2008) 1445-1447. doi:10.1016/j.elecom.2008.07.039.

[120] L. Poltorak, M. Hébrant, M. Afsharian, M. Etienne, G. Herzog, A. Walcarius, Local pH changes triggered by photoelectrochemistry for silica condensation at the liquid-liquid interface, Electrochim. Acta. 188 (2016) 71-77. doi:10.1016/j.electacta.2015.11.107.

[121] H. Jänchenová, K. Štulík, V. Mareček, Preparation of a silicate membrane at a liquid/liquid interface and its doping with a platinum ion, J. Electroanal. Chem. 591 (2006) 41-45. doi:10.1016/j.jelechem.2006.03.036.

[122] M. Guainazzi, G. Silvestri, G. Serravalle, Electrochemical metallization at the liquidliquid interfaces of non-miscible electrolytic solutions, J. Chem. Soc., Chem. Commun. (1975) 200-201. doi:10.1039/C39750000200.

[123] Y. Cheng, D.J. Schiffrin, Electrodeposition of metallic gold clusters at the water / $1,2-$ dichloroethane interface, J. Chem. Soc. Faraday Trans. 92 (1996) 3865-3871.

[124] M. Platt, R.A.W. Dryfe, Electrodeposition at the liquid/liquid interface: The chronoamperometric response as a function of applied potential difference, J. Electroanal. Chem. 599 (2007) 323-332. doi:10.1016/j.jelechem.2006.06.002.

[125] C. Johans, R. Lahtinen, K. Kontturi, D.J. Schiffrin, Nucleation at liquid/liquid interfaces: electrodeposition without electrodes, J. Electroanal. Chem. 488 (2000) 99-109. 
doi:10.1016/S0022-0728(00)00185-6.

[126] C. Johans, K. Kontturi, D.J. Schiffrin, Nucleation at liquid|liquid interfaces: galvanostatic study, J. Electroanal. Chem. 526 (2002) 29-35. doi:10.1016/S00220728(02)00763-5.

[127] A. Trojánek, J. Langmaier, Z. Samec, Random nucleation and growth of Pt nanoparticles at the polarised interface between two immiscible electrolyte solutions, J. Electroanal. Chem. 599 (2007) 160-166. doi:10.1016/j.jelechem.2005.12.004.

[128] D. Izquierdo, A. Martinez, A. Heras, J. Lopez-Palacios, V. Ruiz, R.A.W. Dryfe, et al., Spatial Scanning Spectroelectrochemistry. Study of the Electrodeposition of Pd Nanoparticles at the Liquid/Liquid Interface, Anal. Chem. 84 (2012) 5723-5730. doi:10.1021/ac3009127.

[129] M. Platt, R.A.W. Dryfe, E.P.L. Roberts, Controlled deposition of nanoparticles at the liquid - liquid interface, Chem. Commun. (2002) 2324-2325.

[130] M. Platt, R.A.W. Dryfe, E.P.L. Roberts, Electrodeposition of palladium nanoparticles at the liquid-liquid interface using porous alumina templates, Electrochim. Acta. 48 (2003) 3037-3046. doi:10.1016/S0013-4686(03)00373-6.

[131] M. Platt, R.A.W. Dryfe, E.P.L. Roberts, Structural and electrochemical characterisation of $\mathrm{Pt}$ and $\mathrm{Pd}$ nanoparticles electrodeposited at the liquid/liquid interface, Electrochim. Acta. 49 (2004) 3937-3945. doi:10.1016/j.electacta.2004.02.050.

[132] X. Zhu, Y. Qiao, X. Zhang, S. Zhang, X. Yin, J. Gu, et al., Fabrication of Metal Nanoelectrodes by Interfacial Reactions., Anal. Chem. 86 (2014) 7001-7008. doi:10.1021/ac501119z.

[133] M. Platt, R.A.W. Dryfe, Structural and electrochemical characterisation of Pt and Pd nanoparticles electrodeposited at the liquid/liquid interface: Part 2, Phys. Chem. Chem. Phys. 7 (2005) 1807. doi:10.1039/b418933g.

[134] A. Uehara, T. Hashimoto, R.A.W. Dryfe, Au Electrodeposition at the Liquid-Liquid Interface: mechanistic aspects, Electrochim. Acta. 118 (2014) 26-32. doi:10.1016/j.electacta.2013.11.162.

[135] Y. Gründer, H.L.T. Ho, J.F.W. Mosselmans, S.L.M. Schroeder, R.A.W. Dryfe, Inhibited and enhanced nucleation of gold nanoparticles at the water|1,2-dichloroethane interface., Phys. Chem. Chem. Phys. 13 (2011) 15681-15689. doi:10.1039/c1cp21536a.

[136] R.A.W. Dryfe, A. Uehara, S.G. Booth, Metal Deposition at the Liquid-Liquid Interface, Chem. Rec. 14 (2014) 1013-1023. doi:10.1002/tcr.201402027.

[137] A. Uehara, S.G. Booth, S.Y. Chang, S.L.M. Schroeder, T. Imai, T. Hashimoto, et al., Electrochemical Insight into the Brust-Schiffrin Synthesis of Au Nanoparticles, J. Am. Chem. Soc. 137 (2015) 15135-15144. doi:10.1021/jacs.5b07825.

[138] Y. Li, O. Zaluzhna, Y.J. Tong, Identification of a source of size polydispersity and its solution in Brust-Schiffrin metal nanoparticle synthesis, Chem. Commun. 47 (2011) 6033-6035. doi:10.1039/c1cc11642h.

[139] Y. Li, O. Zaluzhna, B. Xu, Y. Gao, J.M. Modest, Y.J. Tong, Mechanistic Insights into the Brust-Schiffrin Two-Phase Synthesis of Organo-chalcogenate-Protected Metal Nanoparticles, J. Am. Chem. Soc. 133 (2011) 2092-2095. doi:10.1021/ja1105078. 
[140] P.J.G. Goulet, R.B. Lennox, New insights into Brust-Schiffrin metal nanoparticle synthesis, J. Am. Chem. Soc. 132 (2010) 9582-9584. doi:10.1021/ja104011b.

[141] L. Zhu, C. Zhang, C. Guo, X. Wang, P. Sun, D. Zhou, et al., New Insight into Intermediate Precursors of Brust-Schiffrin Gold Nanoparticles Synthesis, J. Phys. Chem. C. 117 (2013) 11399-11404. doi:10.1021/jp402116x.

[142] S.R.K. Perala, S. Kumar, On the Mechanism of Phase Transfer Catalysis in BrustSchiffrin Synthesis of Metal Nanoparticles, Langmuir. 29 (2013) 14756-14762. doi:10.1021/la403652k.

[143] S.G. Booth, A. Uehara, S.Y. Chang, J.F.W. Mosselmans, S.L.M. Schroeder, R.A.W. Dryfe, Gold Deposition at a Free-Standing Liquid/Liquid Interface: Evidence for the Formation of $\mathrm{Au}(\mathrm{l})$ by Microfocus X-ray Spectroscopy ( $\mu$ XRF and $\mu \mathrm{XAFS}$ ) and Cyclic Voltammetry, J. Phys. Chem. C. 119 (2015) 16785-16792. doi:10.1021/acs.jpcc.5b05127.

[144] S.G. Booth, S.Y. Chang, A. Uehara, C. La Fontaine, G. Cibin, S.L.M. Schroeder, et al., In situ XAFS Study of Palladium Electrodeposition at the Liquid/Liquid Interface, Electrochim. Acta. 235 (2017) 251-261. doi:10.1016/j.electacta.2017.03.059.

[145] J. Clohessy, V.J. Cunnane, K. Lepkov, Electrochimica Acta Electrodeposition of metalbased nanocomposites at a liquid - liquid interface controlled via the interfacial Galvani potential difference, 53 (2008) 6273-6277. doi:10.1016/j.electacta.2008.04.025.

[146] G. Schmid, N. Klein, B. Morun, A. Lehnert, J.-O. Malm, Two, four, five-shell clusters and colloids, Pure Appl. Chem. 62 (1990) 1175-1177. doi:10.1351/pac199062061175.

[147] K. Luo, R.A.W. Dryfe, The formation of silver nanofibres by liquid/liquid interfacial reactions: mechanistic aspects, New J. Chem. 33 (2009) 157-163. doi:10.1039/B809654F.

[148] F. Scholz, U. Hasse, Controlling the morphology of silver deposition at liquid|liquid interfaces: From nano-wires to super smooth films, Electrochem. Commun. 7 (2005) 541-546. doi:10.1016/j.elecom.2005.03.010.

[149] Y. Grunder, Q.M. Ramasse, R.A.W. Dryfe, A facile electrochemical route to the preparation of uniform and monoatomic copper shells for gold nanoparticles, Phys. Chem. Chem. Phys. 17 (2015) 5565-5568. doi:10.1039/C4CP05804F.

[150] K. Yao, Q. Huang, W. Lu, A. Xu, X. Li, H. Zhang, et al., A facile synthesis of gold micro/nanostructures at the interface of 1,3-dibutylimidazolium bis(trifluoromethylsulfonyl)imide and water, J. Colloid Interface Sci. 480 (2016) 30-38. doi:10.1016/j.jcis.2016.06.074.

[151] N. Nishi, T. Kakinami, T. Sakka, Dendritic nanofibers of gold formed by the electron transfer at the interface between water and a highly hydrophobic ionic liquid, Chem. Commun. 51 (2015) 13638-13641. doi:10.1039/C5CC05476A.

[152] V.J. Cunnane, U. Evans, Formation of oligomers of methyl- and phenyl-pyrrole at an electrified liquid/liquid interface, Chem. Commun. (1998) 2163-2164. doi:10.1039/a806365f.

[153] K. Gorgy, F. Fusalba, U. Evans, K. Kontturi, V.J. Cunnane, Electropolymerization of $2,2^{\prime \prime}: 5^{\prime}, 2^{\prime \prime}$ terthiophene at an electrified liquid-liquid interface, Synth. Met. 125 (2002) 
$365-373$.

[154] H.H. Girault, Electrochemistry at liquid-liquid interfaces, in: A.J. Bard, C.G. Zoski (Eds.), Electroanal. Chem. Vol. 23, CRC Press, Boca Raton, 2010: pp. 1-104.

[155] U. Evans-Kennedy, J. Clohessy, V.J. Cunnane, Spectroelectrochemical Study of $2,2^{\prime}: 5^{\prime}, 2^{\prime \prime}$-Terthiophene Polymerization at a Liquid/Liquid Interface Controlled by Potential-Determining lons, Macromolecules. 37 (2004) 3630-3634. doi:10.1021/ma0348223.

[156] M. Vignali, R. Edwards, V.J. Cunnane, Characterization of doping and electropolymerization of free standing films of polyterthiophene, J. Electroanal. Chem. 592 (2006) 37-45. doi:10.1016/j.jelechem.2006.04.020.

[157] M. Vignali, R.A.H. Edwards, M. Serantoni, V.J. Cunnane, Electropolymerized polythiophene layer extracted from the interface between two immiscible electrolyte solutions: Current-time analysis, J. Electroanal. Chem. 591 (2006) 59-68. doi:10.1016/j.jelechem.2006.03.033.

[158] K. Maeda, H. Jänchenová, A. Lhotský, I. Stibor, J. Budka, V. Mareček, Formation of a polymer layer from monomers adsorbed at a liquid | liquid interface, J. Electroanal. Chem. 516 (2001) 103-109. doi:10.1016/S0022-0728(01)00658-1.

[159] V. Mareček, H. Jänchenová, I. Stibor, J. Budka, Compact poly-pyrrole layers formed at a liquid|liquid interface, J. Electroanal. Chem. 575 (2005) 293-299. doi:10.1016/j.jelechem.2004.09.021.

[160] T. Kakiuchi, H. Sasao, Electrochemical dediazoniation of arenediazonium ions and subsequent radical polymerization at the liquid-liquid interface, Russ. J. Electrochem. 44 (2008) 73-77. doi:10.1007/s11175-008-1011-z.

[161] C. Johans, J. Clohessy, S. Fantini, K. Kontturi, V.J. Cunnane, Electrosynthesis of polyphenylpyrrole coated silver particles at a liquid-liquid interface, Electrochem. Commun. 4 (2002) 227-230. doi:10.1016/S1388-2481(02)00256-4.

[162] K. Lepková, J. Clohessy, V.J. Cunnane, The pH-controlled synthesis of a gold nanoparticle / polymer matrix via electrodeposition at a liquid - liquid interface, J. Phys. Condens. Matter. 19 (2007) 0-12. doi:10.1088/0953-8984/19/37/375106.

[163] R. Knake, A.W. Fahmi, S.A.M. Tofail, J. Clohessy, M. Mihov, V.J. Cunnane, Electrochemical nucleation of gold nanoparticles in a polymer film at a liquid-liquid interface, Langmuir. 21 (2005) 1001-1008. doi:10.1021/la048277q.

[164] P.S. Toth, A.K. Rabiu, R.A.W. Dryfe, Controlled preparation of carbon nanotubeconducting polymer composites at the polarisable organic/water interface, Electrochem. Commun. 60 (2015) 153-157. doi:10.1016/j.elecom.2015.08.022.

[165] P.S. Toth, A.K. Rabiu, R.A.W. Dryfe, Controlled preparation of carbon nanotubeconducting polymer composites at the polarisable organic/water interface, Electrochem. Commun. 60 (2015) 153-157. doi:10.1016/j.elecom.2015.08.022.

[166] H. Zhu, L. Gao, M. Li, H. Yin, D. Wang, Fabrication of free-standing conductive polymer films through dynamic three-phase interline electropolymerization, Electrochem. Commun. 13 (2011) 1479-1483. doi:10.1016/j.elecom.2011.09.029.

[167] M. Li, H. Zhu, X. Mao, W. Xiao, D. Wang, Electropolymerization of polypyrrole at the three-phase interline: Influence of polymerization conditions, Electrochim. Acta. 92 
(2013) 108-116. doi:10.1016/j.electacta.2013.01.016.

[168] H. Zhu, M. Li, D. Wang, S. Zhou, C. Peng, Interfacial Synthesis of Free-Standing Asymmetrical PPY-PEDOT Copolymer Film with 3D Network Structure for Supercapacitors, J. Electrochem. Soc. . 164 (2017) A1820-A1825. doi:10.1149/2.1401707jes.

[169] A. Gergely, G. Inzelt, Electropolymerization of 3-methylthiophene at liquid 3methylthiophene | aqueous solution | graphite three-phase junction, Electrochem. Commun. 3 (2001) 753-757. doi:10.1016/S1388-2481(01)00261-2.

[170] E. Bak, M. Donten, M. Skompska, Z. Stojek, Electrodeposition of poly(N-vinylcarbazole) at the three-phase junction. Formation of very different polymer structures, J. Phys. Chem. B. 110 (2006) 24635-24641. doi:10.1021/jp063935w.

[171] L. Gao, X. Mao, H. Zhu, W. Xiao, F. Gan, D. Wang, Electropolymerization of PEDOT on CNTs conductive network assembled at water/oil interface, Electrochim. Acta. 136 (2014) 97-104. doi:10.1016/j.electacta.2014.05.053.

[172] D. Li, Y. Li, Y. Feng, W. Hu, W. Feng, Hierarchical graphene oxide/polyaniline nanocomposites prepared by interfacial electrochemical polymerization for flexible solid-state supercapacitors, J. Mater. Chem. A. 3 (2015) 2135-2143. doi:10.1039/C4TA05643D.

[173] Y. Song, J.-B. Fan, S. Wang, Recent progress in interfacial polymerization, Mater. Chem. Front. 1 (2017) 1028-1040. doi:10.1039/C6QM00325G.

[174] P. Dallas, V. Georgakilas, Interfacial polymerization of conductive polymers: Generation of polymeric nanostructures in a 2-D space, Adv. Colloid Interface Sci. 224 (2015) 46-61. doi:10.1016/j.cis.2015.07.008.

[175] R. Mishra, S. Gupta, A. Kumar, R. Prakash, Morphology-controlled approach for bulk synthesis of conducting poly (5-aminoindole), Mater. Chem. Phys. 183 (2016) 606614. doi:10.1016/j.matchemphys.2016.09.023.

[176] D.D. Sawall, R.M. Villahermosa, R.A. Lipeles, A.R. Hopkins, Interfacial Polymerization of Polyaniline Nanofibers Grafted to Au Surfaces, Chem. Mater. 16 (2004) 1606-1608. doi:10.1021/cm0352908.

[177] R. Gupta, M. Singhal, S.K. Nataraj, D.N. Srivastava, A potentiostatic approach of growing polyaniline nanofibers in fractal morphology by interfacial electropolymerization, RSC Adv. 6 (2016) 110416-110421. doi:10.1039/C6RA21759A.

[178] H.Y. Ma, Y.Q. Luo, S.X. Yang, Y.W. Li, F. Cao, J. Gong, Synthesis of aligned polyaniline belts by interfacial control approach, J. Phys. Chem. C. 115 (2011) 12048-12053. doi:10.1021/jp201411y.

[179] J. Huang, R.B. Kaner, A General Chemical Route to Polyaniline Nanofibers, J. Am. Chem. Soc. 126 (2004) 851-855. doi:10.1021/ja0371754.

[180] K. Su, N. Nuraje, L. Zhang, I.W. Chu, R.M. Peetz, H. Matsui, et al., Fast conductance switching in single-crystal organic nanoneedles prepared from an interfacial polymerization-crystallization of 3,4-ethylenedioxythiophene, Adv. Mater. 19 (2007) 669-672. doi:10.1002/adma.200602277.

[181] D.W.M. Arrigan, Nanoelectrodes, nanoelectrode arrays and their applications, Analyst. 129 (2004) 1157-1165. 
[182] S.M. Oja, M. Wood, B. Zhang, Nanoscale Electrochemistry, Anal. Chem. 85 (2013) 473-486. doi:10.1021/ac3031702.

[183] M.D. Scanlon, J. Strutwolf, A. Blake, D. Iacopino, A.J. Quinn, D.W.M. Arrigan, Iontransfer electrochemistry at arrays of nanointerfaces between immiscible electrolyte solutions confined within silicon nitride nanopore membranes, Anal. Chem. 82 (2010) 6115-6123. doi:10.1021/ac1008282.

[184] M. Sairi, N. Chen-Tan, G. Neusser, C. Kranz, D.W.M. Arrigan, Electrochemical Characterisation of Nanoscale Liquid|Liquid Interfaces Located at Focused Ion BeamMilled Silicon Nitride Membranes, ChemElectroChem. 2 (2015) 98-105. doi:10.1002/celc.201402252.

[185] M.D. Scanlon, D.W.M. Arrigan, Enhanced Electroanalytical Sensitivity via Interface Miniaturisation: Ion Transfer Voltammetry at an Array of Nanometre Liquid-Liquid Interfaces, Electroanalysis. 23 (2011) 1023-1028. doi:10.1002/elan.201000667.

[186] M. Rimboud, R.D. Hart, T. Becker, D.W.M. Arrigan, Electrochemical behaviour and voltammetric sensitivity at arrays of nanoscale interfaces between immiscible liquids, Analyst. 136 (2011) 4674-4681. doi:10.1039/c1an15509a.

[187] M. Sairi, J. Strutwolf, R.A. Mitchell, D.S. Silvester, D.W.M. Arrigan, Chronoamperometric response at nanoscale liquid-liquid interface arrays, Electrochim. Acta. 101 (2013) 177-185. doi:10.1016/j.electacta.2012.11.062.

[188] Y. Liu, M. Sairi, G. Neusser, C. Kranz, D.W.M. Arrigan, Achievement of Diffusional Independence at Nanoscale Liquid-Liquid Interfaces within Arrays, Anal Chem. 87 (2015) 5486-5490. doi:10.1021/acs.analchem.5b01162.

[189] Y. Liu, J. Strutwolf, D.W.M.M. Arrigan, Ion-Transfer Voltammetric Behavior of Propranolol at Nanoscale Liquid-Liquid Interface Arrays, Anal Chem. 87 (2015) 44874494. doi:10.1021/acs.analchem.5b00461.

[190] R.A.W. Dryfe, S.M. Holmes, Zeolitic rectification of electrochemical ion transfer, J. Electroanal. Chem. 483 (2000) 144-149. doi:10.1016/S0022-0728(99)00506-9.

[191] G.C. Lillie, R.A.W. Dryfe, S.M. Holmes, Zeolite-membrane modulation of simple and facilitated ion transfer, Analyst. 126 (2001) 1857-1860. doi:10.1039/b105056g.

[192] S. Senthilkumar, R.A.W. Dryfe, R. Saraswathi, Size-selective voltammetry: modification of the interface between two immiscible electrolyte solutions by zeolite Y., Langmuir. 23 (2007) 3455-3461. doi:10.1021/la0626353.

[193] T. Hinoue, E. Ikeda, S. Watariguchi, Y. Kibune, Thermal Modulation Voltammetry with Laser Heating at an Aqueous |Nitrobenzene Solution Microinterface: Determination of the Standard Entropy Changes of Transfer for Tetraalkylammonium lons, Anal. Chem. 79 (2007) 291-298. doi:10.1021/ac061315I.

[194] M.J. Stephenson, S.M. Holmes, R.A.W. Dryfe, Electrochemically controlled ion exchange: proton exchange with sodium zeolite Y., Angew. Chem. Int. Ed. 44 (2005) 3075-8. doi:10.1002/anie.200463036.

[195] Y. Chen, S. Bian, K. Gao, Y. Cao, H. Wu, C. Liu, et al., Studies on the meso-sized selectivity of a novel organic/inorganic hybrid mesoporous silica membrane, J. Memb. Sci. 457 (2014) 9-18. doi:10.1016/j.memsci.2014.01.035.

[196] X. Jiang, K. Gao, D. Hu, H. Wang, S. Bian, Y. Chen, lon-transfer voltammetric 
determination of folic acid at meso-liquid-liquid interface arrays, Analyst. 140 (2015) 2823-2833. doi:10.1039/C4AN02011A.

[197] M. Platt, R.A.W. Dryfe, E.P.L. Roberts, Voltammetry with Liquid / Liquid Microarrays : Characterization of Membrane Materials, Langmuir. 19 (2003) 8019-8025.

[198] L. Xie, X. Huang, X. Lin, B. Su, Nanoscopic liquid/liquid interface arrays supported by silica isoporous membranes: Trans-membrane resistance and ion transfer reactions, J. Electroanal. Chem. 784 (2017) 62-68. doi:10.1016/j.jelechem.2016.12.007.

[199] X. Huang, L. Xie, X. Lin, B. Su, Permselective Ion Transport Across the Nanoscopic Liquid/Liquid Interface Array, Anal. Chem. 88 (2016) 6563-6569. doi:10.1021/acs.analchem.6b01383.

[200] L. Xie, X. Huang, B. Su, Portable Sensor for the Detection of Choline and Its Derivatives Based on Silica Isoporous Membrane and Gellified Nanointerfaces, ACS Sensors. 2 (2017) 803-809. doi:10.1021/acssensors.7b00166.

[201] A.N.J. Rodgers, S.G. Booth, R.A.W. Dryfe, Particle deposition and catalysis at the interface between two immiscible electrolyte solutions (ITIES): A mini-review, Electrochem. Commun. 47 (2014) 17-20. doi:10.1016/j.elecom.2014.07.009.

[202] R. Lahtinen, H. Jensen, D.J. Fermin, Catalysis and Photocatalysis at Polarized Molecular Interfaces : An Electrochemical Approach to Catalytic Processes Based on Two-Phase Systems, Self-Organized Microheterogeneous Structures and Unsuported Nanoparticles, in: A.G. Volkov (Ed.), Interfacial Catal., CRC Press, 2003.

[203] P. Peljo, M.D. Scanlon, A.J. Olaya, L. Rivier, E. Smirnov, H.H. Girault, Redox Electrocatalysis of Floating Nanoparticles: Determining Electrocatalytic Properties without the Influence of Solid Supports, J. Phys. Chem. Lett. 8 (2017) 3564-3575. doi:10.1021/acs.jpclett.7b00685.

[204] J.J. Nieminen, I. Hatay, P. Ge, M.A. Méndez, L. Murtomäki, H.H. Girault, Hydrogen evolution catalyzed by electrodeposited nanoparticles at the liquid/liquid interface, Chem. Commun. 47 (2011) 5548. doi:10.1039/c1cc10637f.

[205] S. Rastgar, M. Pilarski, G. Wittstock, Polarized liquid-liquid interface meets visible light-driven catalytic water oxidation, Chem. Commun. 52 (2016) 11382-11385. doi:10.1039/C6CC04275A.

[206] Y. Gründer, M.D. Fabian, S.G. Booth, D. Plana, D.J. Fermín, P.I. Hill, et al., Solids at the liquid-liquid interface: Electrocatalysis with pre-formed nanoparticles, Electrochim. Acta. 110 (2013) 809-815. doi:10.1016/j.electacta.2013.03.185.

[207] S. Wu, B. Su, Metal-free-porphyrin-catalyzed oxygen reduction at liquid-liquid interfaces, Chem. - A Eur. J. 18 (2012) 3169-3173. doi:10.1002/chem.201103526.

[208] G. Herzog, V. Beni, Stripping voltammetry at micro-interface arrays: A review., Anal. Chim. Acta. 769 (2013) 10-21. doi:10.1016/j.aca.2012.12.031.

[209] G. Herzog, Recent developments in electrochemistry at the interface between two immiscible electrolyte solutions for ion sensing, Analyst. 140 (2015) 3888-3896. doi:10.1039/C5AN00601E.

[210] D.W.M. Arrigan, G. Herzog, Theory of electrochemistry at miniaturised interfaces between two immiscible electrolyte solutions, Curr. Opin. Electrochem. 1 (2017) 6672. doi:10.1016/j.coelec.2017.01.003. 
[211] L. Poltorak, E.J.R. Sudhölter, L.C.P.M. de Smet, Effect of charge of quaternary ammonium cations on lipophilicity and electroanalytical parameters: Task for ion transfer voltammetry, J. Electroanal. Chem. 796 (2017) 66-74.

doi:10.1016/j.jelechem.2017.04.051.

[212] G. Bouchard, P.A. Carrupt, B. Testa, V. Gobry, H.H. Girault, The apparent lipophilicity of quaternary ammonium ions is influenced by galvani potential difference, not ionpairing: A cyclic voltammetry study, Pharm. Res. 18 (2001) 702-708. doi:10.1023/A:1011001914685.

[213] D. Hu, H. Wang, K. Gao, X. Jiang, M. Wang, Y. Long, et al., Anion transfer across "anion channels" at the liquid/liquid interface modified by anion-exchange membrane, RSC Adv. 4 (2014) 57035-57040. doi:10.1039/C4RA09985K.

[214] T.J. Stockmann, Z. Ding, Hydrophobicity of room temperature ionic liquids assessed by the Galvani potential difference established at micro liquid/liquid interfaces, J. Electroanal. Chem. 649 (2010) 23-31. doi:10.1016/j.jelechem.2009.12.024.

[215] T.J. Stockmann, J. Zhang, J.C. Wren, Z. Ding, Hydrophobic alkylphosphonium ionic liquid for electrochemistry at ultramicroelectrodes and micro liquid |liquid interfaces, Electrochim. Acta. 62 (2012) 8-18. doi:10.1016/j.electacta.2011.10.087.

[216] T.J. Stockmann, Z. Ding, Tetraoctylphosphonium Tetrakis(pentafluorophenyl)borate Room Temperature Ionic Liquid toward Enhanced Physicochemical Properties for Electrochemistry, J. Phys. Chem. B. 116 (2012) 12826-12834. doi:10.1021/jp3081832. 